\title{
LA UNESCO Y LA LEY GENERAL DE EDUCACIÓN: LA INFLUENCIA DE LOS ORGANISMOS INTERNACIONALES EN TORNO A LA MODERNIZACIÓN EDUCATIVA EN EL FRANQUISMO*
}

\author{
UNESCO and the Ley General de Educación: the influence \\ of International Organizations arround educational \\ modernization on the Francoism
}

\section{Mariano González-Delgado ${ }^{\alpha}$ y Tamar Groves ${ }^{\beta}$}

Fecha de recepción: 01/09/2020 • Fecha de aceptación: 02/03/2021

\begin{abstract}
Resumen. Este trabajo se centra en analizar la influencia que tuvieron las ideas educativas propuestas por la UNESCO en el desarrollo de la Ley General de Educación (LGE) de 1970. De manera más concreta, se intenta establecer el impacto que ejerció el citado organismo internacional para entender el origen y desarrollo de la LGE durante el franquismo. Para ello, la primera parte del artículo estudia los inicios de la UNESCO en España y cómo se gestó la concepción educativa que daría inicio a una de las reformas educativas más importantes de la España contemporánea. En la
\end{abstract}

\footnotetext{
* Esta investigación ha sido desarrollada bajo los proyectos de investigación: Modernización, desarrollo y democratización. El papel de las potencias europeas occidentales y de las organizaciones internacionales en el cambio político y social en España: PGC2018-097159-B-I00 y Connecting History. Redes internacionales, producción científica y difusión global: PID2019-105328GB-I00, ambos financiados por el Ministerio de Ciencia e Innovación. Agradecemos encarecidamente la ayuda prestada a los técnicos del Archivo General de la Administración, Emilio Rosillo Clement, Aitana Alba Barba y Marina Serrano Muñoz. También nos gustaría agradecer a Jon Igelmo Zaldívar, de la Universidad Complutense de Madrid, la invitación realizada para participar en el seminario «Cultura Cívica y Políticas Educativas» con el fin de discutir una primera versión de este trabajo.

a Dpto. de Historia y Filosofía de la Ciencia, la Educación y el Lenguaje. Área de Teoría e Historia de la Educación, Facultad de Educación, Universidad de La Laguna. C. Pedro Zerolo, s/n. Edificio Central. 456, 28204 San Cristóbal de La Laguna, España. mgondel@ull.edu.es (D) https://orcid. org/0000-0001-9817-9317

в Dpto. de Ciencias de la Educación. Área de Teoría e Historia de la Educación, Facultad de Formación del Profesorado, Universidad de Extremadura. Av. de la Universidad, s/n. 10071 Cáceres, España.tamargroves@unex.es (D) https://orcid.org/0000-0002-0494-6085
}

Cómo citar este artículo: González-Delgado, Mariano y Tamar Groves. «La UNESCO y la Ley General de Educación: la influencia de los organismos internacionales en torno a la modernización educativa en el franquismo». Historia y Memoria de la Educación 14 (2021): 209-252 
segunda parte, se analizan las recomendaciones dadas por el «Comité Asesor Internacional para la Reforma de la Educación en España» en torno al debate que establecieron con el Libro Blanco. La tercera parte del trabajo, por su parte, examina el impacto directo de dicho Comité y cómo sus valoraciones dirigieron el desarrollo de la LGE en sus primeros años de vida. Este trabajo pretende demostrar que la LGE puede entenderse mejor como una reforma nacida al amparo de las recomendaciones de la UNES$\mathrm{CO}$ en torno al contexto educativo originado dentro del marco de la Guerra Fría y la Teoría de la Modernización.

Palabras clave: LGE; UNESCO; planeamiento educativo; franquismo y educación.

Abstract. This article analyzes the influence that the educational ideas proposed by UNESCO had on the development of the General Education Act (LGE) of 1970. More specifically, it attempts to establish the impact that this international organization had on the origin and development of the LGE during the Franco regime. To do so, the first part of the article studies the beginnings of UNESCO in Spain and how the educational conception that would give rise to one of the most important educational reforms of contemporary Spain was developed. In the second part, we examine the recommendations given by the "International Advisory Committee for the Reform of Education in Spain» regarding the debate generated by the Libro Blanco (White Paper). In the third part of the article we look at the Committe's direct impact and the way its assessments guided the development of the LGE in its first years. This work aims to demonstrate that the LGE can be better understood as a reform born under the recommendations of UNESCO regarding the educational context originated within the framework of the Cold War and the Modernization Theory.

Keywords: LGE; UNESCO; educational planning; francoism and education.

\section{INTRODUCCIÓN: HACIA UN PERSPECTIVA TRANSNACIONAL EN EL ANÁLISIS DE LA EDUCACIÓN DURANTE EL FRANQUISMO}

Los procesos de transferencia educativa, influencias extranjeras e intercambio de ideas pedagógicas como objeto de estudio dentro de la Historia de la Educación en España han supuesto una importante línea de investigación en las últimas décadas. ${ }^{1}$ En la actualidad, se puede

\footnotetext{
1 Véase como ejemplo la serie editada por José M. ${ }^{a}$ Hernández Díaz (coord.), Francia en la educación de la España contemporánea (1808-2008) (Salamanca: Ediciones Universidad de Salamanca, 2011) o José
} 
observar, por ejemplo, un número significativo de trabajos que han indicado las conexiones e influencias que se originaron entre los modelos de Escuela Nueva y la política educativa franquista. ${ }^{2}$ Los mismos han ayudado a entender la importancia que las conexiones y relaciones entre países extranjeros, instituciones o personalidades tuvieron a la hora de generar un aggiornamento de la política educativa durante la dictadura franquista. ${ }^{3}$

Por otro lado, desde que la aparición de trabajos como los de Manuel De Puelles Benítez ${ }^{4}$, Agustín Escolano ${ }^{5}$ o Juan Manuel Fernández Soria ${ }^{6}$ mencionaran la importancia que algunos organismos internacionales como la Organización de las Naciones Unidas para la Educación, la Ciencia y la Cultura (UNESCO), la Organización para la Cooperación y el Desarrollo Económicos (OCDE), el Banco Mundial (BM), la Organización de las Naciones Unidas para la Alimentación y la Agricultura (FAO) o la

\footnotetext{
M. ${ }^{a}$ Hernández Díaz (coord.), La pedagogía belga y la innovación educativa en España (1900-1936) (Salamanca: Ediciones Universidad de Salamanca, 2019) en la que se incluyen otras obras que abarcar las influencias italianas, alemanas o suizas en el sistema educativo español; Antonio Viñao, «La recepción de Rousseau en la formación inicial del magisterio primario (España, siglo 20)», Revista História da Educação 17, n. ${ }^{\circ} 41$ (2013): 11-28; María del Mar Del Pozo, "Community and the myth of the ideal school: circulation and appropriation of the Hamburg Gemeinschaftsschulen in Spain (1922-1933)», Paedagogica Historica 50, n. ${ }^{\circ} 5$ (2014): 599-614; Manuel Ferraz Lorenzo, «Un ejemplo de renovación pedagógica en Canarias durante los años 30: Tras el rastro y los retos de las técnicas Freinet», História da Educação 20, n. ${ }^{\circ} 50$ (2016): 157-175; o Javier Fernández Fernández, «Una experiencia pedagógica de la escuela nueva: Carmen Conde y el Orfanato Nacional de El Pardo», Historia y Memoria de la Educación, 10 (2019): 485-521.
}

2 Carlos Martínez Valle, «Active Methods and Social Secularization in School Catechesis during the Franco Dictatorship (1939-1975): A Transfer in a Cultural System in Change», en Catholic Education in the Wake of Vatican II, eds. Rosa Bruno-Jofré y Jon Igelmo-Zaldivar (Toronto: University of Toronto Press, 2017): 69-91; Gabriel Barceló-Bauzà, Francisca Comas-Rubí y María del Mar Del Pozo, «La práctica escolar durante los primeros años del franquismo», História da Educação 22, n. ${ }^{\circ} 54$ (2018): 334-357.

3 María del Mar Del Pozo y Sjaak Braster, «The Reinvention of the New Education Movement in the Franco Dictatorship (Spain, 1936-1976)», Paedagogica Historica 42, n. ${ }^{\circ}$ 1-2 (2006): 109-126; Juan Mainer, La forja de un campo profesional. Pedagogía y didáctica de las Ciencias Sociales en España (1900-1970) (Madrid: CSIC, 2009); Antonio F. Canales, «From soul to matter: the new Spanish Francoist pedagogy's plunge into experimental pedagogy and the influence of Raymond Buyse», Paedagogica Historica 55, n. ${ }^{\circ} 3$ (2019): 451-469.

4 Manuel De Puelles Benítez, Educación e ideología en la España Contemporánea (Barcelona: Labor, 1980).

6 Juan Manuel Fernández Soria, «Presentación. Influencias europeas en la política educativa española del siglo XX (presencias y ausencias, temas para la investigación histórico-educativa)», Historia de la Educación. Revista Interuniversitaria, 24 (2005): 27-37. 
Fundación Ford, pudieron tener en el proceso de modernización de la política educativa durante el tardofranquismo, algunos estudios nuevos han aparecido sobre esta cuestión. ${ }^{7}$ Estos trabajos han puesto de manifiesto el impacto que tuvieron los organismos internacionales para comprender el origen y evolución de algunas políticas educativas y curriculares durante el franquismo. A su vez, los mismos se han beneficiado del interés que ha surgido dentro del campo de la Historia de la Educación a nivel mundial por analizar la importancia que habían tenido los fenómenos de internacionalización en la configuración de las políticas educativas a nivel nacional. ${ }^{8}$ No solo cuestiones relativas al dominio que ejercieron las antiguas potencias imperialistas en la configuración de los sistemas educativos de los países coloniales durante el siglo XIX.9 ${ }^{9}$ Otras líneas de investigación como los vínculos entre personas, instituciones, ideas o viajes también han creado nuevos focos historiográficos que han permitido mejorar la comprensión del ascenso y evoluciones del ámbito educativo a nivel global. ${ }^{10}$

En torno a esta perspectiva, también se han desarrollado investigaciones que han ampliado el espectro de análisis en este sentido. Algunas de ellas, han puesto el énfasis en la importancia que la Guerra Fría y la Teoría de la Modernización han tenido durante la segunda mitad del siglo XX para comprender el cambio orquestado dentro de los sistemas educativos en sus variados espacios organizativos. ${ }^{11}$ Como han indicado Phillip Jones y Daniel Coleman, los sistemas educativos después de la II Guerra Mundial experimentaron una transformación notable. Ello produjo lo

\footnotetext{
7 Gabriela Ossenbach y Alberto Martínez Boom, «Itineraries of the discourses on development and education in Spain and Latin America (circa 1950-1970)», Paedagogica Historica 47, n. 5 (2011): 679-700; Aida Terrón, Josep M. Comelles y Enrique Perdiguero-Gil, «Schools and health education in Spain during the dictatorship of General Franco (1939-1975)», History of Education Review 46, n. ${ }^{\circ} 2$ (2017): 208-223.

8 Gary McCulloch y Roy Lowe, «Introduction: Centre and periphery: networks, space and geography in the history of education», History of Education 32, n. 5 (2003): 457-459; Eckhardt Fuchs, "Children's Rights and Global Civil Society», Comparative Education 43, n. ${ }^{\circ} 3$ (2007): 393-412.
}

9 Joyce Goodman, Gary McCulloch y William Richadson, "Empires overseas' and 'empires at home': postcolonial and transnational perspectives on social change in the history of education", Paedagogica Historica 45, n. ${ }^{\circ}$ (2009): 695-706.

10 Gary McCulloch, The Struggle for the History of Education (London: Routledge, 2011), 93-97.

11 John L. Rudolph, Scientist in the Classroom. The Cold War Reconstruction of American Science Education (New York: Palgrave, 2002); Héctor Lindo-Fuentes, «Educational Television in El Salvador and Modernisation Theory», Journal of Latin American Studies, 41 (2009): 757-792; Óscar J. Martín García, "A complicated mission: The United States and Spanish students during the Johnson administration», Cold War History 13, n. ${ }^{\circ} 3$ (2013): 311-329. 
que estos autores han denominado como una especie de «arquitectura educativa global».12 Un nexo de interconexiones entre países que ejerció una poderosa confluencia para entender los sistemas educativos como uno de los motores de la modernización y crecimiento económico y social de los mismos. La influencia de la Teoría de la Modernización y su difusión por parte de los citados organismos internacionales, ayudó a configurar una suerte de ideas de espectro internacional en torno al desarrollo educativo que permearon en los diferentes estados-nacionales. ${ }^{13}$

Este trabajo tiene por intención analizar el origen y primeras evoluciones de la Ley General de Educación (LGE). El inicio de esta política educativa ofrece un buen ejemplo acerca de la influencia e impacto que tuvieron los organismos internacionales en la modificación y modernización educativa durante la dictadura franquista. De forma más específica, se indica cómo la UNESCO se estableció como ente que desarrolló una nueva concepción educativa en España con la que la dictadura confluyó y puso en marcha de modo paulatino después de la II Guerra Mundial. De esta manera, el origen de la LGE debe entenderse como el resultado de un largo proceso previo centrado en la aceptación de las ideas de carácter funcionalista. Dicho de otro modo, la génesis de la reforma de 1970 se encuentra en la importancia que se otorgó a los sistemas educativos en el proceso de modernización económica y social de los países occidentales durante la Guerra Fría.

No obstante, dentro del campo de la Historia de la Educación también han surgido investigaciones muy recientes que nos hablan de la necesidad de reforzar lo que se ha denominado como historia trasnacional. ${ }^{14}$ Lo que preocupaba a algunos investigadores, era poder explicar

12 Phillip W Jones y David Coleman, The United Nations and Education Multilateralism, Development and Globalization (New York: Routledge, 2005), 48.

13 El inicio de este tipo de trabajos se encuentra en las investigaciones pioneras desarrollas por John W. Meyer, Francisco O. Ramírez, Richard, Rubinson y John Boli, «The World Educational Revolution, 1950-1970», Sociology of Education 50, n. ${ }^{\circ} 4$ (1977): 242-258.

14 Eckhardt Fuchs, «History of Education beyond the Nation? Trends in Historical and Educational Scholarship", en Connecting Histories of Education: Transnational and Cross-Cultural Exchanges on (Post-) Colonial Education, eds. Barnita Bagchi, Eckhardt Fuchs y Kate Rousmaniere, (New York: Berghahn Books, 2014), 11-26; Eugenia Roldán-Vera y Eckhardt Fuchs, «Introducction: The Transnational in the History of Education", en The Transnational in the History of Education: Concepts and Perspectives, eds. Eugenia Roldán-Vera y Eckhardt Fuchs (Cham: Palgrave Macmillan, 2019), 1-47; Gary McCulloch, Ivor Goodson y Mariano González-Delgado, «Introduction. Curriculum history and transnational perspectives for studies: generating debates on educational research", en 
por qué después de la II Guerra Mundial los sistemas educativos a nivel mundial parecían tener las mismas direcciones en sus políticas educativas. A pesar de que los países tuviesen sistemas políticos distintos, tradiciones culturales diversas y estructuras educativas antagónicas, durante la segunda mitad del siglo XX los mismos comenzaron a converger hacia la misma idea o concepto de educación. De esta forma, la categoría de estado-nación como espacio desde el que analizar las políticas educativas empezó a verse como un marco necesario a transformar en pro de una visión transnacional. ${ }^{15}$

La idea a desarrollar se basa en que durante los años indicados una nueva concepción social y educativa se configuró como deseable. El concepto de modernización superó los límites establecidos por los estados-nacionales y estos mismos funcionaron como motores que empujaron hacia esa nueva atmósfera educativa y social.16 A partir de aquí, algunas investigaciones han señalado la necesidad de «replantear dentro de un apropiado contexto internacional» ${ }^{17}$ a los sistemas educativos para entender su origen y evolución de una manera adecuada. El hecho es que, como ha indicado Óscar Martín-García y Rosa Magnúsdóttir, los fenómenos de diplomacia pública entre países - dentro o no de los citados organismos-, configuraron un importante instrumento de «rehabilitación, proyección y aceptación de compromisos entre regímenes de

Transnational Perspectives on Curriculum History, eds. Gary McCulloch, Ivor Goodson y Mariano González-Delgado (London: Routledge, 2020), 1-11; Óscar J. Martín-García y Lorenzo Delgado Gómez-Escalonilla, «Educational Reform, Modernization, and Development: A Cold War Transnational Process», en Teaching Modernization Spanish and Latin American Educational Reform in the Cold War, eds. Óscar J. Martín-García y Lorenzo Delgado Gómez-Escalonilla (New York: Berghahn Books, 2020), 1-39.

15 Ivan L. Christensen y Christian Ydesen, «Routes of Knowledge: Toward a Methodological Framework for Tracing the Historical Impact of International Organizations», European Education 47, n. ${ }^{\circ} 3$ (2015): 274-288.

16 Daniel Trölher, «The technocratic Momentum after 1945, the Development of Teaching Machines, and Sobering Results», Journal of Educational, Media, Memory and Society 5, n. 2 (2013): 1-19; Jon Igelmo-Zaldívar y Gonzalo Jover, «Cuestionando la narrativa del aprendizaje servicio a partir de dos iniciativas de extensión social universitaria de orientación católica en la década de 1950 en España», Utopía y praxis latinoamericana: revista internacional de filosofía iberoamericana y teoría social, 87 (2019): 151-162; Miguel Á. Cabrera, «The discursive origins of the welfare state: Spanish social reformism, 1870-1900», Journal of Social History 52, n. ${ }^{\circ}$ (2019): 1165-1184.

17 Andrea Mariuzzo, «American cultural diplomacy and post-war educational reform: James Bryant Conant's misión to Italy in 1960», History of Education 45, n. 3 (2016): 352-371, 353. 
diferentes puntos de vista políticos». ${ }^{18}$ Un aspecto que nos permite indicar que después de la II Guerra Mundial los organismos internacionales establecieron un fenómeno de universalización y conceptualización de la educación que superó los límites de los márgenes nacionales.

Este artículo se sitúa dentro de la citada perspectiva. Se parte de la idea de que el origen y desarrollo de la LGE durante los años de la dictadura se puede entender de una mejor manera si se inserta dentro de los procesos de modernización e impacto que tuvieron los organismos internacionales durante estos años. Ello nos permite comprender no solo cómo se gestó un determinado concepto sobre educación. También es un marco adecuado para comprender por qué desde finales de la década de los cuarenta del siglo XX, las instituciones educativas franquistas desarrollaron proyectos de modernización educativa relativos a tecnologías educativas, libros de texto o alfabetización y publicaron una cantidad importante de trabajos relacionados con los proyectos propuestos por la UNESCO. ${ }^{19}$ Por tanto, este trabajo intenta analizar el origen y el desarrollo de la LGE entendido como un proceso de carácter transnacional en el que los actores locales también jugaron un destacado papel en el establecimiento de la misma.

\section{LA UNESCO Y EL FRANQUISMO: HACIA LA BÚSQUEDA DE UNA NUEVA CONCEPCIÓN EDUCATIVA}

La UNESCO se creó en 1945 como un organismo especializado de las Naciones Unidas (ONU) para las cuestiones relativas a educación, ciencia y cultura. Su propósito inicial era reconstruir instituciones de carácter

\footnotetext{
18 Óscar J. Martín García y Rosa Mgnúsdottir, «Machineries of Persuasion: European Soft Power and Public Diplomacy during the Cold War», en Machineries of Persuasion: European Soft Power and Public Diplomacy during the Cold War, eds. Óscar J. Martín García y Rosa Mgnúsdottir (Berlin: De Gruyter Oldenbourg, 2019), 1-15, 4.

19 Gabriela Ossenbach y Tamar Groves, «Entre la mitificación y la crítica: el cine y los medios audiovisuales en la escuela primaria en España en el tardofranquismo y la transición, 1958-1982», Cahiers de civilisation espagnole con contemporaine, 11 (2013): 1-12; Mariano González-Delgado, Manuel Ferraz Lorenzo y Cristian Machado-Trujillo, «The concept of the State in textbooks: Analysis and reinterpretation during the Spanish Transition to Democracy (1976-1986)», British Journal of Educational Studies 68, n. ${ }^{\circ} 3$ (2019): 331-347; Kira Mahamud Angulo y Cecilia Milito Barone, «Estancias y consultores para la formación del profesorado. Un pilar estratégico del intercambio cultural ente España y Estados Unidos (1960-1976)», en Modernización educativa y socialización política: Contenidos curriculares y manuales escolares en España durante el tardofranquismo y la transición democrática, ed. Manuel Ferraz Lorenzo (Madrid: Morata, 2020), 151-190.
} 
cultural, educativo y científico destruidas por la guerra con el fin de promover la comprensión internacional, la cooperación y la paz entre países. En cierta medida, se podría indicar que el fin era evitar la repetición de fenómenos como el racismo, la desigualdad entre clases o las visiones maximalistas de carácter nacionalista que originaron las guerras mundiales. ${ }^{20}$ Es evidente que en los años venideros la UNESCO ampliaría su radio de acción. El incremento de programas educativos sería constante y albergaría una rama notable de políticas encaminadas al desarrollo educativo, económico y social. ${ }^{21}$ No es sencillo establecer la influencia e impacto que tuvo la UNESCO durante los primeros años de la dictadura franquista. No obstante, y antes de su entrada oficial en 1952,22 la dictadura parecía estar al corriente de las actividades del organismo internacional desde su origen. De hecho, el Ministerio de Asuntos Exteriores de la dictadura conoció de primera mano el documento sobre la primera «Conferencia Internacional de Ministros de Educación» organizada por la UNESCO en Londres en $1945^{23}$ y la celebrada en Ginebra en 1947 sobre «instrucción pública». ${ }^{24}$ Es más, entre esos dos años, instituciones educativas como el propio Ministerio de Educación Nacional (MEN) o el Instituto San José de Calasanz de Pedagogía se hicieron eco de las propuestas del organismo y publicaron varios artículos concernientes a la UNESCO o a otras instituciones que colaboraban con la misma. ${ }^{25}$

Por otro lado, unos años más tarde, la Real Academia de la Historia recibía un encargo de la UNESCO relacionado con el programa de

\footnotetext{
20 Aigul Kulnazarova y Christian Ydesen, «The nature and methodology of UNESCO's educational campaigns for international understanding», en UNESCO without Borders: Educational campaings for international understanding, eds. Aigul Kulnazarova y Christian Ydesen (London: Routledge, 2017), 3-12.

21 Poul Duedahl, «Out of the House: On the Global History of UNESCO, 1945-2015», en A History of UNESCO: Global Actions and Impacts, ed. Poul Duedahl (London: Palgrave Macmillan, 2016), 3-23.

22 Ángel Oliveros, XXV años de la Comisión Nacional Española de Cooperación con la UNESCO (Madrid: UNESCO-MEC, 1978), 40.

23 «Conferencia Internacional de Ministros de Educación organizado por la UNESCO», noviembre de 1945, Fondo Ministerio de Asuntos Exteriores (10)000.000, legajo R-5927, Exp. 43, Archivo General de la Administración (AGA).

24 «Conferencia Internacional de Instrucción Pública organizada por la UNESCO», 1947, Fondo Ministerio de Asuntos Exteriores (10)000.000, legajo R-2481, Exp. 8, AGA.

25 «Misión y servicio de la Oficina Internacional de Educación», Revista Nacional de Educación, 57 (1945): 67-70; José María Martínez Val, «Educación y pacifismo (La formación del hombre para la paz)», REP 5, n. 18 (1947): 253-268; y John Snowden, "Lazos docentes internacionales», Revista Nacional de Educación, 68 (1947): 91-93.
} 
comprensión internacional. En 1950, dicha institución comenzó a participar en el grupo de trabajo sobre el «Proyecto para una Historia Científica y Cultural de la Humanidad» ${ }^{26}$ que había sido elaborado por historiadores y científicos sociales como Lucien Febvre, Carl J. Burckhardt o Jean Piaget. Los encargados de llevar a cabo dicho proyecto para España serían el Duque de Alba -como presidente-27, Ciriaco Pérez Bustamante, Claudio Sánchez Albornoz o Salvador de Madariaga, entre otros comisarios. ${ }^{28}$ En realidad, el grupo español estaba conformado por una comisión mixta entre personalidades de la dictadura y el Gobierno de la República en el exilio. Seguramente la intención de la UNESCO fuese mantener alguna vía diplomática con España en ambas direcciones en función de cómo se diesen los acontecimientos políticos en un futuro. ${ }^{29}$ El objetivo de dicho proyecto, sería «la producción de libros, charlas, exposiciones... que faciliten la comprensión más amplia de los aspectos científicos y culturales de la humanidad», para desarrollar una idea de «dependencia mutua de los pueblos y de las culturas», como una empresa de "patrimonio común». ${ }^{30}$ Es cierto que hubo alguna reticencia por parte de la dictadura en la conformación de dicho comité. El presidente de la misma recibió alguna carta donde se señalaba el «desagrado» que podía suponer para el Duque de Alba «porque nuestro gobierno no mire con mucha simpatía la idea» de la "participación de Sánchez Albornoz o Madariaga» en la misma. ${ }^{31}$ No obstante, este hecho no supuso un freno a la conformación y desarrollo del proyecto durante el franquismo. En

\footnotetext{
26 «Report on the Project for a Scientific and Cultural History of Mankind», 17 de marzo de 1950, caja Secretaría de la Real Academia de la Historia, Papeles Varios, UNESCO (1951-1983), Archivo de la Real Academia de la Historia (ARAH).

27 «Carta de Jaime Torres Bodet, Director General de la UNESCO, al Duque de Alba», 30 de mayo de 1951, caja Secretaría de la Real Academia de la Historia, Papeles Varios, UNESCO (1951-1983), ARAH.

28 «Comission Internationale Pour une Histoire Scientifique et Culturele de L'Humanite», 3 de noviembre de 1952, p. 5, caja Secretaría de la Real Academia de la Historia, Papeles Varios, UNESCO (1951-1983), ARAH.

29 Sobre los contactos del Gobierno en el exilio con la UNESCO y las reticencias de la UNESCO a señalar dicho gobierno como ente legítimo de España, se puede ver «Letter from Álvaro de Albornoz to the Chairman of Executive Board of UNESCO», 13 de septiembre de 1949, caja 17 EX/31, UNESCO Archive.

30 «Informe para una Historia Científica y Cultural de la Humanidad», 25 de mayo de 1951, p. 1, caja Secretaría de la Real Academia de la Historia, Papeles Varios, UNESCO (1951-1983), ARAH.

31 «Carta de Manuel González-Hontoria al Duque de Alba», 11 de junio de 1951, caja Secretaría de la Real Academia de la Historia, Papeles Varios, UNESCO (1951-1983), ARAH.
} 
1954, con la visita de Luther H. Evans a la Ciudad Universitaria, ${ }^{32}$ ya se había puesto en marcha una exposición de pintura enviada por la UNESCO para la comprensión internacional «con fines educativos» en España. ${ }^{33}$ Incluso, en torno a este proyecto un inspector de enseñanzas medias sugirió «la conveniencia del envío a todos los Institutos de Enseñanza Media de España información detallada... de la citada entidad» y que se propusiese "como tema de redacción para los exámenes del próximo junio un trabajo sobre la UNESCO».34

En este sentido, las propuestas sobre el programa de comprensión internacional fueron de alguna forma divulgadas a través de diferentes instituciones de la dictadura. En torno a estas ideas, comenzaron a llegar a España películas educativas creadas por la UNESCO como «Emancipación de las mujeres», "Derecho a la educación», "Abolición de la esclavitud» o "Qu'est-ce qu' une race?». ${ }^{35}$ En 1952 ya se había firmado un acuerdo para que se permitiera «la libre entrada en España de todas las publicaciones de la UNESCO» sin censura y se fomentase su circulación por el país ibérico. ${ }^{36}$ Incluso, esas mismas películas comenzaron a ser usadas por el Instituto San José de Calasanz dentro del programa de Misiones Pedagógicas para combatir, también, las tasas de analfabetismo. ${ }^{37}$ Todo ello, se acrecentó bajo un programa más amplio encaminado a la cooperación entre países que albergaba la revisión de manuales escolares. De esta forma, a partir de 1951, España firmó un acuerdo con Brasil para revisar de forma bilateral diferentes libros de texto de Historia con el fin de intentar disipar aquellos contenidos que tendiesen a la

\footnotetext{
32 "Carta de Antonio Poch a Pedro Laín Entralgo, visita de Luther Evans a Madrid», 5 de mayo de 1954, caja ES, AGUCM, R-266, Archivo General de la Universidad Complutense de Madrid (AGUCM).

33 «Carta del Embajador de España en París a los Delegados permanentes de España ante la UNESCO», 6 de julio de 1954, Embajada de España en París (10)097.000, caja 54/11502, AGA.

34 "Carta del Ministro de Asuntos Exteriores al Director General de Enseñanza Media», 12 de mayo de 1954, caja ES, AGUCM, R-266, AGUCM.

35 «Carta del jefe de la Oficina de la UNESCO del MEN al Comisario de Extensión Cultural», 26 de febrero de 1954, caja ES, AGUCM, R-266, AGUCM.

36 «Carta de El Conde de Casa Rojas, Embajador de España en París, a Pablo de Berredo Carneiro, UNESCO», 17 de noviembre de 1952, Embajada de España en París (19)097.000, caja 54/11594, AGA.

37 "Catálogos extranjeros de cine educativo, UNESCO», 1954, caja ISJC/25/8, Archivo del Instituto San José de Calasanz de Pedagogía, Residencia de Estudiantes (ISJC).
} 
construcción de prejuicios culturales o ideas de carácter racista. ${ }^{38}$ Estos acuerdos se extenderían con la creación de la Comisión Nacional Española de Cooperación con la UNESCO en 1953. Durante los años siguientes, el programa de «revisión bilateral de los manuales de historia»para la comprensión internacional se firmó también con Francia (1954), ${ }^{39}$ Honduras (1957) o Paraguay (1957). ${ }^{40}$ Los mismos serían realizados por la Real Academia de la Historia pero también por instituciones como el Centro de Documentación y Orientación Didáctica de Enseñanza Primaria (CEDODEP), desde la creación de la misma. ${ }^{41}$

No obstante, el desarrollo de las actividades de la UNESCO no se circunscribió en sus primeros años a las cuestiones específicas sobre comprensión internacional. El uso de los medios audiovisuales como elemento educativo tendente al primer aspecto, pero también al desarrollo económico y social del país, tuvieron una presencia importante en las instituciones educativas de la dictadura. En 1948, el Instituto San José de Calasanz creaba un «Departamento de Filmología» con el objetivo de mejorar los procesos de «alfabetización y desarrollo de las zonas rurales».42 Unos años después el mismo centro bebía directamente de las fuentes UNESCO para el desarrollo de actividades educativas con tales medios. En 1951, Guillermo De Reyna, director del citado departamento, entregaba un informe sobre su asistencia al congreso celebrado por el «Centro Internacional de Cinema Educativo y de Cultura (CIDALC)».43 Un año más tarde, el mismo protagonista acudía a un congreso de la UNESCO celebrado en Milán sobre «estudios de los medios audiovisuales en la educación de base». En el informe que entregó al Instituto San José de Calasanz, el autor indicaba que los citados medios podían ser

\footnotetext{
38 «Revisión de textos escolares en países hispanoamericanos», 1952, Ministerio de Educación (05) 001.029, caja 35619, AGA.

39 «Comisión Nacional Francesa: Revisión de manuales de Historia», 1954-1998, caja 58/ Carpetilla 1, Archivo de la Comisión Nacional Española de Cooperación con la UNESCO (ACNEC-UNESCO).

40 Mariano González-Delgado y Tamar Groves, «Educational Transfer and Local Actors: International Intervention in Spain during the Late Franco Period», en Teaching Modernization Spanish and Latin American Educational Reform in the Cold War, eds. Óscar J. Martín García y Lorenzo Delgado Gómez-Escalonilla (New York: Berghahn Books, 2020), 101-126.

41 Adolfo Maíllo, «La comprensión entre Oriente y Occidente», Vida Escolar, 4 (1959): 42-44.

42 "Carta de Víctor García Hoz a Guillermo de Reyna», 17 septiembre de 1948, caja ISJC/25/6, ISJC.

43 «Memoria de la representación española en la asamblea general del Centro Internacional del Cinema Educativo y de Cultura (CIDALC)», 15 de noviembre de 1951, caja ISJC/4/1, ISJC.
} 
importantes para «las poblaciones retrasadas» con el objetivo de ayudarles «a comprender los problemas del medio en que viven». Dicho de otra manera, podían servir para que las zonas rurales tuviesen «una justa idea de sus derechos y deberes tanto cívicos como individuales» o para que pudiesen "participar más eficazmente en el progreso económico y social de la humanidad».44 Como el propio De Reyna escribiese poco después, los medios audiovisuales fueron vistos como una herramienta «capaz de realizar las más profunda renovación económica y cultural en las comunidades más atrasadas de nuestra patria». ${ }^{45}$ Lo importante a destacar de esta cuestión, es que estas ideas fueron los lemas principales que se volverían a reproducir en diferentes seminarios o congresos que se organizaron en España sobre esta cuestión bajo acuerdos con la UNESCO. Baste señalar, como ejemplo, los organizados en Tánger en $1955^{46}$ o Valencia en $1960 .{ }^{47}$

No nos deben extrañar la aparición de este tipo de trabajos en España por estas fechas. Desde sus inicios, la UNESCO había puesto en marcha determinados trabajos sobre el uso de los medios audiovisuales como instrumento para el desarrollo económico. Como ha indicado Suzanne Langlois, desde 1945 la UNESCO vio en el uso de películas una "poderosa herramienta para la modernización» de los países en vías de desarrollo».48 Emile McAnany también ha señalado cómo desde finales de los años cuarenta del siglo XX, la UNESCO se había convertido en un «rápido consumidor» de la literatura estadounidense sobre medios de comunicación y desarrollo. En particular, estuvo muy interesada en los trabajos de Wilburn Schramm sobre el uso de la televisión como un método educativo que podía alcanzar grandes cotas de modernización

\footnotetext{
44 Guillermo De Reyna y Juan Juez Vicente, «Congreso de estudio de los medios audiovisuales en la educación de base. Memoria de los representantes del Consejo Superior de Investigaciones Científicas asistentes al mismo», 16 de mayo de 1952, p. 9, caja ISJC/4/3, ISJC.

45 Guillermo De Reyna, «Los métodos audio-visuales en la educación fundamental. Notas al congreso de Milán», Revista de Educación 1, n. ${ }^{\circ} 2$ (1952): 164-167, 167.

46 «Carta de Juan Esterlich al Embajador de España en París», 14 de febrero de 1955, Embajada de España en París (10)097.000, caja 54/11594, AGA.

47 «Memoria sobre la XI Conferencia General de la UNESCO y sobre las actividades de la Comisión Nacional Española», 15 de diciembre de 1960, caja ES, AGUCM, R-300, AGUCM.

48 Susanne Langlois, "And Action! UN and UNESCO Coordinating Information Films, 1945-1951», en A History of UNESCO: Global Actions and Impacts, ed. Poul Duedahl (London: Palgrave Macmillan, 2016), 73-94, 73.
} 
económica. Años más tarde, Schramm se convertiría en uno de los principales técnicos de la UNESCO en el desarrollo de este tipo de programas en diferentes países. ${ }^{49}$

Sin embargo, durante los años en que se desarrollaron los programas indicados, comenzó a originarse de forma paralela un proceso que modificaría la política educativa durante el franquismo. Nos referimos a los acontecimientos iniciados a principios de los años cincuenta entre las instituciones educativas franquistas y la UNESCO. En 1952, el Ministerio de Asuntos Exteriores recibía una carta del director de la UNESCO John W. Taylor. En ella, se invitaba al comité ejecutivo español a aportar sus observaciones acerca del "grupo de trabajo sobre el programa y desarrollo futuros de la UNESCO.$^{50}$ Entre los documentos a comentar, se encontraba el relativo al programa de trabajo de la VIII Conferencia General de la UNESCO que se celebraría en Montevideo entre el 12 de noviembre y el 11 de diciembre de 1954 y que sería el primero al que acudiese la delegación española con voz y voto. Al año siguiente, el comité ejecutivo español de la UNESCO emitía una serie de observaciones sobre dicho programa. En ellas, se señaló que el comité «muestra su conformidad en principio» a todo lo que hacía referencia a la "campaña en pro de la enseñanza gratuita y obligatoria», al igual que la «educación de adultos» en la medida en que todo ello se observaba como un elemento fundamental para la búsqueda del desarrollo. ${ }^{51}$ Por primera vez, las instituciones educativas franquistas aceptaban y convergían con una idea fundamental que acababa de poner sobre la mesa la UNESCO. Nos referimos a la idea de que los sistemas educativos y la universalización de los mismos eran un eje fundamental para el desarrollo económico. Pero no solo. Al mismo tiempo se daba por válida una nueva concepción educativa. Nos referimos a la idea de que los sistemas educativos se deben establecer en relación a las necesidades de desarrollo económico de los países. Por tanto, desde el MEN se aceptaba una premisa básica de la

\footnotetext{
49 Emile G. McAnany, Saving the World: A Brief History of Communication for Development and Social Change (Baltimore: University of Illinois Press, 2012), 20.

50 «Carta de J. W. Taylor al Ministerio de Asuntos Exteriores», 10 de diciembre de 1952, caja ES, AGUCM, R-266, AGUCM.

51 «Observaciones españolas al documento 7G/PGR/39 relativo al programa y desarrollo futuro de la UNESCO», 29 de agosto de 1953, p. 10, caja ES, AGUCM, R-266, AGUCM.
} 
Teoría de la Modernización y, al mismo tiempo, se observaba como deseable la idea de planeamiento educativo. ${ }^{52}$

Después de la celebración del congreso de Montevideo, la concepción sobre la política educativa caminaría en este sentido. El discurso que el ministro de Educación ofreció en dicha conferencia dejaba pocas dudas al respecto. En el mismo, Joaquín Ruiz- Giménez reconocía que un principio fundamental que debía regir en todos los espacios educativos era el «principio de igualdad sustancial de todos los hombres y todos los pueblos... sin distinción de razas ni de clases sociales». ${ }^{53}$ Es más, parafraseando la nueva visión educativa que había desarrollado la UNESCO, indicaba la necesidad de generar «la elevación social de los sectores económicamente más débiles en todos los pueblos» a través de la educación. ${ }^{54}$ En este mismo sentido, se expresaba la delegación española que acudió a dicho congreso. En el informe que emitieron Manuel Fraga Iribarne o José Luis Villar Palasí, entre otros, sobre la asistencia a dicha conferencia, se señalaba cómo la delegación española realizó una «defensa de la labor de esta conferencia» y de las ideas propuestas por la UNESCO. ${ }^{55}$

Este tipo de afirmaciones acerca de la necesidad de planear o planificar el sistema educativo en relación al desarrollo económico no deberían sorprendernos. Como el mismo Ricardo Díez-Hochleitner afirmaría años después de la puesta en marcha de la LGE, «en 1955, el entonces ministro de Educación Nacional, Joaquín Ruiz-Giménez... declaró su aspiración de preparar en el plazo de un año "tal vez una ley o Fuero general de la Educación desde la Enseñanza Primaria hasta nuestras Universidades" ». Un hecho que, como el propio Díez-Hochleitner reconocería, le «impactó considerablemente por aquellas fechas».56 De hecho, durante los primeros años de la década de los cincuenta del siglo XX, el MEN

52 Sobre la Teoría de la Modernización y su relación con la educación, véase Óscar Martín-García, «Una utopía secular. La teoría de la modernización y la política exterior estadounidense en la Guerra Fría», Historia y Política, 34 (2015): 27-52.

53 Joaquín Ruiz-Giménez, «España, en la UNESCO», Revista de Educación, 26 (1954): 157-160, 157.

54 Ruiz-Giménez, «España, en la UNESCO», 160.

55 «Carta de Manuel Fraga Iribarne al presidente del Comité Ejecutivo de la UNESCO, Pedro Laín Entralgo», 21 de enero de 1955, p. 11, caja ES, AGUCM, R-266, AGUCM.

56 Ricardo Díez-Hochleitner, «La reforma educativa de la LGE de 1970. Datos para una crónica», Revista de Educación n. ${ }^{\circ}$ ext. «La Ley General de Educación veinte años después» (1992): 261-278, 262. 
comenzó a establecer políticas educativas enmarcadas dentro del desarrollo económico y social. Nos referimos aquí, por ejemplo, a la Ley de Construcciones Escolares (1953 y 1956), el aumento de los presupuestos para la Comisaría de Protección Escolar (1956), ${ }^{57}$ la promulgación de los Cuestionarios Nacionales para la Enseñanza Primaria (1953), la Ley de Ordenación de Enseñanza Medias (1953) o la Ley de Formación Profesional Industrial (1955).58 En realidad, el MEN venía a desarrollar las ideas sobre planeamiento educativo que se habían erigido como centrales dentro de la UNESCO desde principio de los años cincuenta. Un aspecto que se aceleraría a partir de 1963 con la creación del Instituto de Planeamiento Educativo por parte del citado organismo. ${ }^{59}$

A pesar de la destitución de Ruiz-Giménez como ministro de educación en 1956, la concepción educativa desplegada por las instituciones educativas de la dictadura seguiría por los mismos cauces. Un hecho importante marcaría un punto de inflexión sobre esta cuestión. En 1954 un técnico francés de la UNESCO recibía una beca a cargo del «Patronato Raimundo Lulio» a desarrollar en el Instituto San José de Calasanz centrada en "la educación en relación con los medios sociales». ${ }^{60} \mathrm{Su}$ nombre era Jacques Bousquet y ese mismo año hasta 1960 sería asesor técnico del MEN. Cargo que repetiría desde 1969 hasta 1973 para el desarrollo de la LGE. ${ }^{61}$ En 1957, Bousquet publicaba un artículo en la $R e-$ vista de Educación. En el mismo, el autor insistía en la necesidad de «replantear la educación completamente». Señalaba la importancia de adoptar una nueva concepción educativa que se "percatase de que las instituciones creadas en el curso de los cien años últimos son extremadamente ineficaces» y que por tanto era preciso «refundir en su totalidad» las mismas. Dicho de otro modo, «el problema no consiste en reformar parcelas concretas o en imitar un poco de esto o de lo otro,

\footnotetext{
57 «Panorama económico de la protección escolar», Revista de Educación, 71 (1957): 58-60.

58 Escolano, «Los comienzos de la modernización pedagógica en el Franquismo (1951-1964)», $291-298$.

59 Jones y Coleman, The United Nations and Education Multilateralism, Development and Globalization, 61-90. Véase también, el informe de la UNESCO «Emergency Programme of Financial aid to member states and associate member in Africa: International aid for Educational Planning», noviembre de 1961, caja WS/0961.9, UNESCO Archive.

60 «Contrato de colaboración, Patronato Raimundo Lulio, Instituto San José de Calasanz al prof. Jacques Bousquet», 3 de febrero de 1954, caja ISJC/18/8, ISJC.

61 Jacques Bousquet, La problemática de las reformas educativas (Madrid: MEC, 1974), 3.
} 
sino en replantear la educación completamente». ${ }^{62}$ En realidad, el autor hacía referencia a la necesidad de planear el sistema educativo en su totalidad en relación con las metas del desarrollo económico y social. Por tanto, en hacer pivotar el sistema educativo desde una visión elitista hacia la promoción de las masas con el fin de desarrollar al máximo el capital humano disponible.

En este mismo sentido se pronunciaría el, por entonces, secretario general del Consejo Nacional de Educación, Fraga Iribarne. En 1953 organizaba en Santander un ciclo sobre "La Educación en una sociedad de masas».63 En ellas, el autor expresaba la necesidad de modernizar el sistema educativo español y adaptarlo al desarrollo. Fraga insistía en el interés de «ampliar»y «planificar» el sistema educativo. Se trataba de «obligar al Estado a un mayor control de la educación» para, entre otras cosas, "prolongar el período de escolaridad obligatoria». ${ }^{64} \mathrm{Un}$ aspecto que diferentes técnicos del MEN conocían directamente por su participación en diferentes conferencias de la UNESCO como la «Conferencia de enseñanza obligatoria y gratuita» celebrada en 1953,65 la reunión sobre "Las causas del fracaso en las escuelas» en $1956^{66}$ o la reunión sobre «Estudio de los problemas de la Protección escolar» en 1959.67 Incluso, en la reunión de 1959, José Navarro Latorre como comisario de la Protección Escolar del MEN, fue «elegido Vicepresidente de la Asociación Internacional de la Información Escolar Universitaria y Profesional y Protección escolar», creada por la UNESCO en 1959.68 A raíz de las primeras aproximaciones sobre esta

62 Jacques Bousquet, «Replantear el problema de la educación», Revista de Educación, 69 (1957): 1-4, 1 y 3. Similares argumentos en Manuel Utande Igualada, «Una Ley general de Educación», Revista de Educación, 99 (1959): 1-3.

63 Manuel Fraga Iribarne, ed., La educación en una sociedad de masas (Madrid: Cultura Hispánica, 1954).

64 Visto en José María Ortiz de Solórzano, «La educación en una sociedad de masas», Revista de Educación, 14 (1953): 237-243, 238.

65 «Conferencia regional sobre la enseñanza gratuita y obligatoria», 1953, Ministerio de Asuntos Exteriores (10)000.000, caja 82/10522, AGA.

66 «Reunión sobre curso de fracaso en las escuelas organizado por la UNESCO», 1956, Ministerio de Asuntos Exteriores (10)000.000, caja 82/13593, AGA.

67 «Reunión de la Comisión Internacional Permanente para el estudio de los problemas de la protección escolar convocada por la UNESCO», 1959, Ministerio de Asuntos Exteriores (10)000.000, caja 82/13593, AGA.

68 «Informe sobre la Reunión de la Comisión Internacional Permanente sobre Protección Escolar», 1959, Ministerio de Asuntos Exteriores (10)000.000, caja 82/13593, AGA. 
cuestión, comenzaron a aparecer trabajos sobre la «conveniencia social de la democratización de la enseñanza» o de la importancia de fomentar «la igualdad de oportunidades para las familias con rentas bajas» con el fin de modernizar y mejorar el desarrollo económico a través del incremento del «capital humano».69

Después de la aparición de estos primeros artículos sobre la necesidad de planear y reformar el sistema educativo como elemento de desarrollo, la cuestión se aceleraría en la década de los sesenta. El propio ministro de educación, Jesús Rubio García-Mina, lo pondría de manifiesto en el discurso dado en la XI Conferencia General de la UNESCO en 1961. El ministro indicaba la necesidad de "hacer un esfuerzo para lograr un mayor rigor en la planificación» del sistema educativo. Al mismo tiempo, señalaba que no se podía articular los programas educativos en «una pululación de iniciativas inconexa». Más bien, aspiraba a que las reformas educativas se «articulasen e integrasen en su conjunto, sí. A ello, queremos tender, en efecto». ${ }^{70}$ Por otro lado, justo ese año se organizó un foro entre la OCDE y la UNESCO para el desarrollo de una serie de programas de asistencia técnica en España. En el pequeño informe que se publicó sobre el mismo, se señalaban varias valoraciones que la dictadura debería tener presente. Se proponía, entre otras cosas, «que España emprenda un vasto programa de desarrollo de la enseñanza adaptándola a su plan de crecimiento económico y social». Para ello, se recomendaba, a su vez, que el MEN ampliase el «acceso a la enseñanza de las clases con ingresos inferiores», que redujese la "desigualdad existente entre unas regiones y otras en el acceso a la cultura» o que fomentase «el acceso de la enseñanza a las mujeres». Por su parte, el propio MEN reconocía lo adecuado de las recomendaciones. Se afirmaba que, en realidad, «a eso vamos. Mejor dicho, no tenemos más remedio que ir a eso». ${ }^{71}$

$\mathrm{Al}$ año siguiente, España entraba en el Proyecto Regional Mediterráneo (PRM). Con ello, se estrechaba el círculo en torno a la concepción

\footnotetext{
69 Feliciano Lorenzo Gelices, «El derecho a la enseñanza y su protección jurídica por el estado y la sociedad: sus problemas», Revista de Educación, 80 (1958): 61-66, 61 y 63.

70 Jesús Rubio García-Mina, «Importante discurso del Ministro de Educación nacional en la UNESCO», Vida Escolar, 25 (1961): 25-29, 26.

71 «OCDE: Desarrollo de la enseñanza española», Revista de Educación, 175 (1965): 89.
} 
educativa que la vinculaba como uno de los motores del desarrollo económico. En el informe publicado, se indicaba la necesidad, de nuevo, de establecer una «norma» hacia la "planificación de la enseñanza» que se integre en la «estrategia del desarrollo económico». Por primera vez, la OCDE no establecía el acceso a la escolarización como elemento principal. Como el propio informe reconocía, «procurar un aumento cuantitativo de la educación primaria no es lo único importante, también lo es el aumentarlo en calidad». Es decir, había que mejorar «el equipo necesario» en las escuelas y los «maestros capaces de dirigirlos», así como el programa de «igualdad de oportunidades» y el «acceso a la Universidad» o perfeccionar la «educación de adultos». ${ }^{72}$

Las recomendaciones indicadas por la OCDE y la UNESCO no cayeron en saco roto. Pronto, el MEN se puso manos a la obra. Justo en 1961, y en colaboración con la UNESCO, el MEN organizaba una serie de «misiones de estudio sobre planeamiento educativo». ${ }^{73}$ Además, al año siguiente, también se organizaron otra serie de conferencias sobre este tema. En ellas, se volvieron a expresar una serie de ideas muy similares a las establecidas por la UNESCO y la OCDE. Se insistía en que «una planificación total de la educación viene siendo desde hace años una de las preocupaciones fundamentales del MEN». Por tanto, ante «la estrecha coordinación entre educación y desarrollo económico y social» era necesario dar la «máxima prioridad a la inversión educativa», «reestructurar la organización, contenido y métodos de la enseñanza», o perfeccionar los «sistemas de selección, formación y perfeccionamiento del profesorado en los distintos niveles» para alcanzar las metas de modernización económica y social. ${ }^{74}$ Pero las actividades llevadas a cabo sobre esta nueva concepción educativa no solo se extendían dentro de las estructuras del propio MEN. De manera paralela, el CEDODEP organizaba cursos patrocinados por la UNESCO para la formación del profesorado con el

\footnotetext{
72 OCDE-MEN, «la educación española en el desarrollo económico», Revista de Educación, 147 (1962): 25-29, 25-28. Lorenzo Delgado Gómez-Escalonilla, «Modernizadores y tecnócratas. Estados Unidos ante la política educativa y científica de la España del Desarrollo», Historia y Política, 34 (2015): 113-146.

73 MEN, España y la UNESCO. Colaboración al Proyecto Principal Extensión y Perfeccionamiento de la Educación Primaria en América Latina (Madrid: MEN, 1962), 16.

74 MEN-UNESCO, La educación y el desarrollo económico-social. Planeamiento integral de la educación. Objetivos de España para 1970 (Madrid: MEN-UNESCO, 1962), 5 y 199.
} 
objetivo de modernizar las aulas ${ }^{75}$ o creaba publicaciones como Notas y Documentos para dar salida a los debates educativos que se generaban en el ámbito internacional. ${ }^{76}$ Por otro lado, la Sociedad Española de Pedagogía (SEP) y el Instituto San José de Calasanz dedicaron el III Congreso Nacional de Pedagogía a «El sistema educativo español en función de las necesidades económicas y sociales» en el que se abogaba por realizar una «revisión total del sistema escolar», impulsar la «educación permanente» y promulgar una «Ley de bases de todo el sistema escolar».77 En este mismo sentido, una cantidad importante de artículos científicos relativos a la importancia del planeamiento educativo vieron la luz a lo largo de la década de los sesenta. ${ }^{78}$

Pero el desarrollo de esta nueva concepción educativa no se quedaba exclusivamente en la publicación de artículos, la realización de conferencias o cursos. Durante la década de los sesenta el MEN creó una cantidad importante de proyectos educativos en esta dirección. Todos ellos estuvieron relacionados con propuestas o programas que había desarrollado o desarrollaba la UNESCO durante estos años. Aquí no nos referimos de forma exclusiva al aumento de puestos escolares de enseñanza primaria o media, ${ }^{79}$ la ley "sobre ampliación del período de escolaridad obligatoria hasta los catorce años», ${ }^{80}$ los nuevos «Cuestionarios Nacionales de enseñanza primaria»,81 o la ley "sobre ordenación de

75 CEDODEP, La escuela unitaria completa: Curso organizado por el Gobierno español como colaboración al Proyecto Principal de la UNESCO (Madrid: CEDODEP, 1960).

76 Baste como ejemplo indicar que el primer número de Notas y Documentos abrió con el siguiente artículo: Joaquín Tena Artigas, «Economía y Educación», Notas y Documentos, 1 (1961): 3-8.

77 Víctor García Hoz, «Discurso de clausura», REP 23, n. ${ }^{\circ} 91-92$ (1965): 845-862, 846 y 862.

78 Ambrosio J. Pulpillo, «Planeamiento del trabajo escolar por cursos», Vida escolar, 51-52 (1963): 5-7; Adolfo Maíllo, «La Escuela Media, necesidad nacional», Revista de Educación, 155 (1963): 109118; «Planeamiento escolar y necesidades económico sociales», Revista de Educación, 170 (1965): 134135; Juan Manuel Paredes Grosso, «Notas actuales sobre educación y desarrollo», Revista de Educación, 179 (1966): 122-127; «La UNESCO y la investigación sobre planeamiento», Revista de Educación, 191 (1967): 144.

79 «Educación y desarrollo», Revista de Educación, 178 (1966): 93.

80 Ley 27/1964, de 29 de abril, sobre ampliación del período de escolaridad obligatoria hasta los catorce años, BOE n. ${ }^{\circ} 107$ de 4 de mayo de 1964.

81 Orden de 8 de julio de 1965 por la que se aprueban los cuestionarios que han de regir todas las actividades didácticas en las Escuelas Primarlas, BOE n. ${ }^{\circ} 229$ de 24 de septiembre de 1965. 
enseñanzas medias». ${ }^{82}$ Quizá lo más importante, desde el punto de vista de una reforma del sistema educativo y la idea de planeamiento educativo haya sido la vinculación del sistema educativo con los Planes del Desarrollo. ${ }^{83}$ En torno a ellos, se comenzaron a poner en marcha medidas encaminadas a modernizar el sistema educativo para alcanzar los estándares de crecimiento económico previstos para la década de los setenta. De esta forma, durante estos años se crearon proyectos educativos como el Centro Nacional de Enseñanza Media por Radio y Televisión y el Bachillerato RTV (1963), propuestas curriculares como la enseñanza programada, los Teleclubs (1964) o Televisión Escolar (1968). ${ }^{84}$ Además, se intentó mejorar la estructura cuantitativa y cualitativa de la enseñanza con la creación del «Fondo nacional para el fomento del principio de igualdad de oportunidades (PIO)»,85 la modernización de la administración educativa con la transformación del antiguo MEN por el Ministerio de Educación y Ciencia (MEC) ${ }^{86}$ o la "planificación general de la investigación [incluida la educativa] en relación con las necesidades del desarrollo económico y social». .8

A pesar de los esfuerzos realizados por el MEN y el MEC durante estos años, la UNESCO no parecía estar convencida del todo acerca de las propuestas implantadas. Entre octubre y noviembre de 1968 llegó a España una Misión de inspección liderada por la UNESCO relativa a las acciones llevadas a cabo dentro del PRM y con la mirada puesta en las reformas educativas futuras. La misma estuvo compuesta por especialistas de la UNESCO, el BM y la Organización de las Naciones Unidas

82 Ley 24/1963, de 2 de marzo, sobre modificación de la Ley de Ordenación de la Enseñanza Media en cuanto a las pruebas de grado y de madurez, BOE n. ${ }^{\circ} 55$ de 5 de marzo de 1963.

83 Antonio Tena Artigas, «La Educación y el primer Plan de Desarrollo», Revista de Educación, 180 (1966): 26-31.

${ }^{84}$ Mariano González-Delgado y Tamar Groves, «La enseñanza programada, la UNESCO y los intentos por modificar el currículum en la España desarrollista (1962-1974)», Espacio, Tiempo y Educación 4, n. ${ }^{\circ} 2$ (2017): 73-100; y Mariano González-Delgado y Tamar Groves, «UNESCO mediation in Francoist curriculum policy: The case of educational television in Spain», en Transnational Perspectives on Curriculum History, eds. Gary McCulloch, Ivor Goodson y Mariano González-Delgado (London: Routledge, 2020), 83-107.

85 Ley 45/1960, de 21 de julio, por el que se crean determinados Fondos Nacionales para la aplicación social del Impuesto y del Ahorro, BOE n. ${ }^{\circ} 176$ de 23 de julio de 1960.

86 «El Ministro de Educación y Ciencia explica la política del nuevo Ministerio», Revista de Educación, 178 (1966): 90.

87 «Investigación y desarrollo», Revista de Educación, 190 (1967): 85-86, 86. 
para la Alimentación y la Agricultura (FAO). La finalidad de dicha Misión fue «revisar los actuales planes de desarrollo del sistema educativo y hacer una investigación preliminar sobre los posibles sectores prioritarios de inversión». ${ }^{88}$ Es cierto que los especialistas enviados «evaluaron de manera positiva» las acciones que se habían efectuado. Sin embargo, la Misión pedía más esfuerzos hacia el planeamiento y el desarrollo económico. Para ellos, las transformaciones realizadas tenían «una débil vinculación entre el Plan [de desarrollo] y el programa de reformas». ${ }^{89}$ El problema estaba en que todavía la «educación en general carece de un contacto sistemático con la industria», pero también con la "orientación selectiva del sistema», con un «enfoque demasiado conservador de los planes de estudio» o con un «elevado índice de deserciones» en la enseñanza media..$^{90}$ La Misión lo tenía claro, "el sistema escolar español necesita un cambio radical». ${ }^{91}$ Según las recomendaciones dadas, ese cambio radical solo podría ponerse en marcha a través de diferentes proyectos educativos. El primero hacía referencia a dar mayor prioridad al planeamiento a través de la creación de un "plan general educativo a largo plazo».92 Lo que se traducía en aumentar la inversión y planificar la «investigación sobre el desarrollo de los planes de estudio», "dar una alta prioridad a la investigación científica y tecnológica», fomentar la «igualdad de oportunidades para todos» y la «orientación educativa y profesional» o crear «instituciones experimentales».93 No obstante, una de las preocupaciones fundamentales de la Misión fue el problema relativo a las «necesidades de personal docente» y la investigación en educación. El objetivo era que el propio personal de las reformas se implicase en las mismas y así evitar que no se produjese un "verdadero plan de educación». ${ }^{44}$ La orientación de la política educativa, por tanto, parecía estar clara y la respuesta del MEC en esta dirección sería inmediata.

\footnotetext{
88 «España. La Reforma de la Educación. Informe Preliminar (Confidencial EFM/17)», febrero de 1969, p. 1, caja UIL 370.51 Sp ARCHIV, UNESCO Archive.

89 «España. La Reforma de la Educación», 2.

90 «España. La Reforma de la Educación», 3-16.

91 «España. La Reforma de la Educación», 36.

92 «España. La Reforma de la Educación», 29.

93 «España. La Reforma de la Educación», 37-40.

94 «España. La Reforma de la Educación», 33.
} 


\section{LAS REUNIONES DEL COMITÉ INTERNACIONAL PARA LA REFORMA EDUCATIVA Y EL LIBRO BLANCO: LA UNESCO AL PODER}

Como hemos podido observar, 1968 sería un año clave desde un punto de vista educativo. Dadas las recomendaciones indicadas por la Misión UNESCO-BIRD-FAO la necesidad de desarrollar una ley educativa de carácter estructural se observaba como un hecho incontestable. La idea de planeamiento no solo era el mástil sobre el que pivotaba la UNESCO. Desde hacía años la dictadura también veía en ese sendero el espacio que se debía recorrer para alcanzar las cotas de desarrollo y modernización ancladas en el contexto occidental. Así las cosas, el régimen incorporó ese mismo año a un nuevo ministro de Educación, Villar Palasí, y a uno de los técnicos que dirigía el Departamento de Planeamiento y Financiación Educativa de la UNESCO, Díez-Hochleitner como secretario general técnico del MEC. El objetivo principal era poner en marcha una reforma educativa de todo el sistema que, por fin, solucionase los problemas de carácter educativo y socioeconómicos que no se habían enmendado años atrás.

Bajo este marco, lo primero que se hizo dentro del MEC en 1968, por sugerencia directa de Díez-Hochleitner, fue hacer un requerimiento al BM para comenzar el «cambio radical» que la misión anterior había propuesto. Como ha señalado David Corrales, el régimen necesitaba de estos fondos para poder emprender tan amplia tarea. De hecho, la cesión de los fondos entraría dentro del nuevo acuerdo que la UNESCO y el BM habían firmado en 1967 para desarrollar proyectos educativos en diferentes países en vías de desarrollo. Un acuerdo en el que también entrarían otras organizaciones como la Fundación Ford. ${ }^{95}$ Una vez aceptado el programa para la cesión de fondos, el MEC se puso a trabajar sobre la reforma educativa. Uno de los primeros pasos a seguir sería el de poner en marcha un centro para la formación del profesorado. Nos referimos a la creación del Centro Nacional de Investigaciones para el Desarrollo de la Educación y la red de Institutos de Ciencias de la Educación (CENIDE-ICEs). ${ }^{96}$ No nos debe

\footnotetext{
95 David Corrales Morales, «Much Ado about Nothing? Lights and Shadows of the World Bank's Support of Spanish Aspirations to Educational Modernization (1968-1972)», en Teaching Modernization Spanish and Latin American Educational Reform in the Cold War, eds. Óscar J. Martín García y Lorenzo Delgado Gómez-Escalonilla (New York: Berghahn Books, 2020), 127-149, 131-133.

96 Jacques Bousquet, "El Centro Nacional de Investigaciones para el Desarrollo de la Educación», Perspectivas, 0 (1972): 155-159; Gonzalo Jover y Blanca Thoilliez Ruano, «La pedagogía «au pluriel»
} 
extrañar la decisión tomada por el MEC. Como hemos indicado más arriba, la Misión entendió que una de las acciones más importantes para poner en marcha las reformas previstas estaba en la investigación educativa para el desarrollo y la formación del profesorado. Por tanto, el CENIDE era un proyecto promovido por los organismos internacionales. Creado en 1969, comenzó a recibir financiación de la Fundación Ford, dentro del programa de cesiones mencionado. De hecho, en paralelo a su creación, la Fundación Ford otorgó unos fondos para establecer un primer viaje a EE. UU. para importar o producir procesos de transferencia educativa y ver cómo se podía desarrollar dicha institución en España. ${ }^{97}$

Aunque el CENIDE recibió los pequeños fondos mencionados, no será hasta 1972 que se apruebe y firme respectivamente el plan de operaciones con el Programa de las Naciones Unidades para el Desarrollo (PNUD) que otorgase una financiación más consistente al nuevo centro. Denominado "SPANED 19», se trataba de un subproyecto de asistencia requerida por el Gobierno de España para el desarrollo económico. ${ }^{98} \mathrm{La}$ red CENIDE/ICEs se constituyó como un ente federativo que se encargaba de coordinar los Institutos del Ciencias de la Educación (ICEs) en torno a una «triple responsabilidad de investigación, formación y experimentación». Tales propósitos se desarrollarían a través de una serie de seminarios a celebrar en la sede del propio CENIDE o en la red de los ICEs adscritos. La intención declarada era «obtener la mayor rentabilidad posible» del sistema educativo y convertir este aspecto en «una cuestión preliminar de urgente actualidad». 99

Sin embargo, el impacto de la Misión no se quedaría en este punto. Al tiempo que se creaba el CENIDE, el MEC también puso en marcha la elaboración del Libro Blanco. ${ }^{100}$ Este informe o estudio preliminar sobre

\footnotetext{
y su incidencia en la reformulación del conocimiento teórico de la educación en España», en Francia en la educación de la España contemporánea (1808-2008), coord. José María Hernández Díaz (Salamanca: Universidad de Salamanca, 2011): 219-247.

97 «Informe sobre el viaje a Estados Unidos de la Comisión de Profesores Universitarios encargados de estudiar la organización de los Institutos de Ciencias de la Educación», Revista de Educación, 206 (1969): 55-60.

98 "Country and Intercountry Programming. UNDP assistance requested by the Goverment of Spain for period 1972-1976», 5 de septiembre de 1973, p. 15, caja 75/Carpetilla 1, ACNEC-UNESCO.

99 «El CENIDE y las investigaciones sobre educación», Revista de Educación, 209 (1970): 5-14, 5.

100 MEC, La educación en España. Bases para una política educativa (Madrid: MEC, 1969).
} 
cómo se tendría que desarrollar la LGE recogió en gran medida las propuestas que habían sido sugeridas por la Misión UNESCO-BIRD-FAO. Desde la misma «Introducción» se pueden observar las orientaciones en este sentido. Villar Palasí reconocía, por ejemplo, que "gran parte de las líneas generales de la reforma han sido ya elaborados por comisiones asesoras expertas», ${ }^{101}$ lo que suponía toda una declaración de intenciones por parte del citado Libro sobre hacia dónde iría encaminada la reforma. No obstante, otros ejemplos también nos ponen sobre aviso de la influencia ejercida por la Misión. Una página después, el ministro señalaba que en realidad el tema de las llamadas «reivindicaciones universitarias» acaparó «la atención general, por cuanto tiene de "noticia"» pero que en "gran medida» el problema no se encontraba ahí sino "en los anteriores niveles educativos». Dicho de otra manera, el problema estaba en las cuestiones que habían señalado los expertos internacionales como «el clasismo» de la enseñanza media, «el sentido dogmático de la enseñanza» o «la actitud de pasividad intelectual a que se somete el alumnado, polarizado únicamente a la superación de unos exámenes memorísticos».102

Por otro lado, las llamadas a una reforma integral del sistema educativo no paraban de escucharse desde otro tipo de foros. De nuevo, Bousquet -una década después de su artículo de 1957 en este mismo sentido y convertido ahora en Advanced Training Programme (ATP) UNESCO para el desarrollo del CENIDE- volvía a interpelar a los lectores de la Revista de Educación, haciendo suyas las palabras de la misión UNESCO-BIRD-FAO sobre la necesidad de llevar a cabo «no unas cuantas reformas de detalle sino una revisión completa y, quizá, cambios radicales» del sistema educativo. ${ }^{103}$ Ahora bien, este tipo de artículos no venían exclusivamente de los técnicos implicados en la reforma. Otros autores, relacionados con el CEDODEP o el Instituto San José de Calasanz también se sumaban a la importancia que tenía establecer una reforma educativa estructural bajo el marco del planeamiento educativo. ${ }^{104}$

\footnotetext{
101 MEC, La educación en España, 8.

102 MEC, La educación en España, 9.

103 Jacques Bousquet, «Tendencias del Planeamiento educativo en 1968», Revista de Educación, 201 (1969): 43-47, 44.

104 Francisco González-Arizmendi, «La evolución actual de la enseñanza profesional (Notas tomadas de informes de la OCDE)», Revista de Educación, 202 (1969): 65-68; Juan Noriega Álvarez,
} 
No obstante, durante el año 1969 se abriría otra puerta que implicaba un mayor acercamiento de la reforma a las propuestas lanzadas por la UNESCO. Durante el año 1968 tuvo lugar la XV Conferencia General de la UNESCO. En ella, el organismo internacional aprobó un programa de actividades para países de desarrollo medio-alto cuyo objetivo era ayudarles con la aplicación y desarrollo de reformas y planes educativos. La dictadura, a través de los contactos internacionales de Díez-Hochleitner, solicitó asistencia técnica en el marco de dicho programa. El propósito era constituir un comité de expertos internacionales que pudieran ayudar al MEC en la realización y desarrollo de la reforma. La ayuda sería concedida por la UNESCO a principios del año 1969.105 El Comité de Cooperación Internacional para la Reforma Educativa en España estuvo compuesto por diferentes técnicos de la UNESCO. Su presidente fue Gabriel Betancur, antiguo ministro de Educación en Colombia que había tenido a Díez-Hochleitner como técnico en dicho ministerio. Otros especialistas del comité fueron Philip H. Coombs, antiguo director del Instituto Internacional de Planeamiento Educativo de la UNESCO, Giovanni Gozzer, técnico de la UNESCO y director del Centro Europeo dell'Educazione, o John Vaizey, técnico de la UNESCO y profesor de economía en la Brunel University. ${ }^{106}$ Una vez compuesto el Comité, se celebraron dos reuniones en Madrid y Toledo entre marzo y noviembre de 1969. El objetivo era que el Comité debatiese el Libro Blanco y diese recomendaciones para la puesta en marcha de la LGE.

Los comentarios realizados fueron de diferente naturaleza. En la primera reunión se acordó «aceptar los problemas sugeridos por el Ministerio». Al Comité le pareció bien que se discutiese acerca de la «Investigación Educativa», la «Educación Permanente», la «Evaluación del Rendimiento educativo» y la "Cooperación Internacional en la Reforma». No obstante, incluyó un punto que se desarrollaría en la segunda reunión y que para el Comité era de vital importancia. Nos referimos a

\footnotetext{
«Bases para el Planeamiento de la biblioteca escolar como centro de proyección cultural», Vida Escolar, 113-114 (1969): 16-27; Víctor García Hoz, «Reforma cualitativa de la educación», REP 30, n. ${ }^{\circ} 127$ (1972): 3-10.

105 «Carta de Emilio Garrigues (delegado permanente de España ante la UNESCO) a Ricardo Díez-Hochleitner», 2 de febrero de 1969, caja 342/Carpetilla 2, ACNEC-UNESCO.

106 «Miembros del Comité de Cooperación Internacional para la Reforma de la Educación en España», 1969, caja 342/Carpetilla 2, ACNEC-UNESCO.
} 
la «estrategia y táctica de la Reforma educativa». ${ }^{107} \mathrm{~A}$ pesar de que los miembros del Comité «felicitaron a los responsables» del MEC por los "extraordinarios adelantos» hechos en los años previos a la puesta en marcha de la LGE, diferentes recomendaciones fueron expuestas. La primera de ellas, hacía referencia al primer punto discutido. Para los expertos del Comité había un problema claro. La investigación educativa había sido desarrollada hasta la fecha bajo "unos criterios excesivamente estrechos». Había estado desconectada de la realidad y tenía que relacionarse con «la sociedad y economía a la que sirve». Para ello, el Comité indicó prestar «especial atención a los nuevos medios (televisión, radio, etc.) y a las técnicas autoinstructivas tales como la enseñanza programada, la utilización pedagógica de los ordenadores y al propio libro». 108 Por otro lado, se insistió sobremanera en que la Reforma hiciese un esfuerzo por desarrollar la «educación permanente», debido a la «aceleración de los cambios de las profesiones». Era necesario «hacer de los individuos personas educables que puedan continuar su propio aprendizaje a lo largo de toda su vida». También se recomendó estrechar la «participación española con los actuales proyectos del Instituto Internacional de Planeamiento Educativo» o promover «seminarios internacionales» en el CENIDE sobre «economía de la educación».109

La segunda reunión volvería a repetir las cuestiones a debatir. El Comité, de nuevo, insistía sobre la necesidad de mejorar y poner en marcha las «tecnologías educativas», la «investigación educativa» en relación a las necesidades del desarrollo y el planeamiento de la reforma o fomentar la «educación permanente». ${ }^{110}$ Sin embargo, en este segundo grupo de valoraciones también se hicieron nuevas recomendaciones al MEC. El Comité consideró como elemento necesario «participar»en «el proyecto internacional sobre rendimiento educativo y comparado dirigido por el profesor Thorsten Husén, de Suecia». La intención era analizar los datos de rendimiento «bajo el anterior sistema selectivo... y bajo la nueva política». Es decir, intentar fomentar el principio de «igualdad de

\footnotetext{
107 «Informe final del Comité de Cooperación Internacional para la Reforma de la Educación en España», Revista de Educación, 202 (1969): 58-64, 58.

108 «Informe final del Comité», 59-60.

109 «Informe final del Comité», 60-63.

110 «II Reunión del Comité de Cooperación Internacional para la Reforma de la Educación en España», Revista de Educación, 205 (1969): 54-58.
} 
oportunidades». ${ }^{111}$ Tras estas sugerencias, otra de mayor urgencia fue expuesta por el Comité. Para los expertos internacionales la estrategia sobre cómo poner en marcha la reforma les preocupaba bastante. De hecho, habían insistido muchísimo en la necesidad de planear muy bien la investigación educativa que se iba a desarrollar en la red CENIDE-ICEs. Pero también, les preocupaba mucho la formación e implicación del profesorado en la reforma. Esta cuestión era definida como una de las que «mayor dificultad podía presentar». El Comité se hacía la siguiente pregunta: «¿Cómo podrían miles de profesores que han sido entrenados y han ejercido según el antiguo sistema educativo llegar a adquirir una perspectiva y un estilo considerablemente diferentes?». En efecto, a los expertos les preocupaba la cuestión relacionada con la cultura escolar y las diferencias que podían existir entre los reformadores y el mundo de la escuela. Para ello, insistieron en «indagar más seriamente acerca de la investigación educativa» $\mathrm{y}$ «financiar visitas» del profesorado en torno a los temas propuestos. ${ }^{112}$

\section{EL IMPACTO DEL COMITÉ DE LA UNESCO EN LOS PRIMEROS AÑOS DE LA LGE}

La LGE se promulgó el 4 de agosto de 1970, poco después de las reuniones del Comité Internacional. ${ }^{113}$ Describir la influencia que tuvo la UNESCO en la LGE se antoja una empresa amplia. La UNESCO no solo estuvo detrás del desarrollo mismo de la reforma. En realidad, como hemos visto, la concepción educativa que se gestó desde principios de los años cincuenta a través de las propuestas de la UNESCO fue central y nos da la clave sobre el origen de la propia LGE. Aun así, el impacto más directo también puede estudiarse a través de cómo las instituciones educativas del franquismo gestionaron y llevaron a la práctica las valoraciones hechas por el Comité Internacional para la Reforma.

En este sentido, las respuestas a las recomendaciones indicadas fueron inmediatas. Justo después de que se hiciesen públicas las primeras

\footnotetext{
111 «II Reunión del Comité», 56.

112 «II Reunión del Comité», 55.

113 Ley 14/1970, de 4 de agosto, General de Educación y Financiamiento de la Reforma Educativa, BOE n. ${ }^{\circ} 187$ de 6 de agosto de 1970.
} 
recomendaciones del Comité, apareció un artículo en Revista de Educación bajo el sugerente título de "La dificultad número uno».114 Se trataba de un trabajo centrado en analizar la estrategia sobre el desarrollo práctico de la LGE. Para su autora, Ángeles Galino, «el hándicap número uno» para poner en marcha la reforma estaba relacionado con «la falta de formación adecuada del profesorado» y, por tanto, con las cuestiones relativas a la cultura escolar. La misma autora añadía, a su vez, que era necesario "comprometer varios departamentos ministeriales» si se quería aspirar a desarrollar una "política de la educación con medianos vuelos». ${ }^{115}$ Pero este mismo argumento no solo fue expuesto por Galino. Desde el MEC se apresuraron a publicar artículos de los mismos expertos que habían sido miembros del Comité. En ese mismo año, apareció otro artículo de Gozzer sugiriendo elementos muy similares. ${ }^{116}$ Para el técnico italiano de la UNESCO estaba claro que una de las causas «más profunda de la actual crisis educacional es la inercia congénita de los sistemas escolares». ${ }^{117}$ Otros autores, como algunos miembros del Instituto San José de Calasanz también realizaron comentarios en este sentido. ${ }^{118}$ Incluso su director, Víctor García Hoz, se hacía eco de las recomendaciones del Comité e indicaba que «la reforma educativa está condenada al fracaso si no puede contar con un núcleo de profesores suficientemente amplio y eficazmente dispuestos a seguir la línea de la educación renovada». ${ }^{119}$

Por otro lado, la huella de las recomendaciones dadas por el Comité también se dejó notar en torno a las otras temáticas sugeridas. Entre 1970 y 1971, la Revista de Educación publicó tres artículos del profesor Husén tal y como el mismo Comité había sugerido. ${ }^{120}$ Lo importante a destacar aquí, es que la publicación de estos artículos -como se reconocía en el

\footnotetext{
114 Ángeles Galino, «La dificultad número uno», Revista de Educación, 203 (1969): 7-13.

115 Galino, «La dificultad número uno», 7 y 8.

116 Giovanni Gozzer, «Consideraciones sobre la "inercia" de las estructuras educacionales», Revista de Educación, 206 (1969): 7-11.

117 Gozzer, «Consideraciones sobre la "inercia”», 7.

118 Francisco Secadas, «Criterios para una reforma de la educación», REP 57, n. ${ }^{\circ} 105$ (1969): 3-56.

119 García Hoz, «Reforma cualitativa de la educación», 5.

120 Torsten Husén, «Dos décadas de investigación educativa en Suecia», Revista de Educación, 210211 (1970): 12-26; Torsten Husén, «Reforma y tradición del sistema escolar ante las necesidades cambiantes de la sociedad: algunas experiencias suecas», Revista de Educación, 212-213 (1971):
} 
«Prólogo» del número de 1970- era fruto del «nuevo rumbo para la continua renovación de nuestra enseñanza» que había suscrito el MEC con los organismos internacionales. ${ }^{121}$ Aunque con temáticas distintas, los tres artículos versaban sobre los mismos debates. El primero, estaba relacionado con la necesidad de introducir la «nueva tecnología» en el ámbito educativo como una forma de «mejora escolar» pero también como una herramienta que podía facilitar la «formación permanente» y la adaptación de los individuos a los nuevos «conocimientos de las ocupaciones».122 El segundo, versaba sobre la cuestión relativa al desarrollo práctico de la reforma. Al igual que Galino o García Hoz, el autor sueco indicaba la necesidad de fortalecer la formación del profesorado. Estos últimos podían ser los "guardianes del establecimiento»y, por tanto, hacer fracasar la reforma. ${ }^{123}$ Por último, una de las cuestiones sobre las que más insistió el profesor Husén era la necesidad de fortalecer la «igualdad de oportunidades». Para el autor, las políticas fundamentales para producir el cambio educativo venían de los espacios «socioeconómicos» como hecho fundamental previo a toda modificación escolar. ${ }^{124}$ Por tanto, la igualdad de oportunidades se erigía en una premisa fundamental para el éxito educativo. ${ }^{125}$

Bajo este marco, el MEC no se quedó con los brazos cruzados. Independientemente de que una de las novedades principales de la LGE fue la promoción del "principio de igualdad de oportunidades»,126 el desarrollo de dicho principio no se detuvo en este punto. Hacia finales del año 1974 , los programas relativos a la igualdad de oportunidades sufrieron un proceso de cambio y modernización en el ámbito administrativo. El PIO, creado en 1961, fue sustituido por un nuevo servicio llamado

53-58; y Torsten Husén, «El modelo de las escuelas del mañana», Revista de Educación, 215-216 (1971): 93-104.

121 «Prólogo», Revista de Educación, 210-211 (1970): 4.

122 Husén, «El modelo de las escuelas del mañana», 93 y 94.

123 Husén, «Reforma y tradición del sistema escolar», 56.

124 Husén, «Reforma y tradición del sistema escolar», 53.

125 Debemos tener presente que la obra más importante que se publicó en España del autor sueco fue editada por el MEC y llevo por título: Torsten Husén, Para una igualdad de oportunidades (Madrid: ICCE y INCIE/MEC, 1978).

126 Ley 14/1970, de 4 de agosto, General de Educación y Financiamiento de la Reforma Educativa, BOE n. ${ }^{\circ} 187$ de 6 de agosto de 1970, 12526. 
Instituto Nacional de Asistencia y Promoción del Estudiante (INAPE). Entre sus objetivos no estuvo solo gestionar todo lo relacionado con las becas de estudio. También se intentaron desarrollar nuevos programas de apoyo a la igualdad de oportunidades como una mayor "flexibilidad de gestión y promoción personalizada del estudio» o el respaldo a «instituciones sociales tales como mutualidades, cotos escolares y cooperativas». ${ }^{127}$ Por otro lado, durante los primeros años de la puesta en marcha de la LGE, el MEC publicó diferentes monográficos de la Revista de Educación centrados en este debate. Títulos como «igualdad de oportunidades», 128 «Acceso a la educación superior» 129 O «Problemas de la Educación Postsecundaria»130 vieron la luz entre 1973 y 1974.

No obstante, las publicaciones que aparecieron durante estos años no estuvieron relacionadas de forma exclusiva con la igualdad de oportunidades. Hemos señalado la importancia que fue concedida a las tecnologías aplicadas al mundo de la educación como una forma de alcanzar un mayor desarrollo económico. Así, una cantidad importante de trabajos sobre esta nueva herramienta educativa u otras sugeridas por el Comité fueron impresos en las páginas de la Revista de Educación en este momento. ${ }^{131}$ Incluso, se publicaron numerosos trabajos sobre organismos internacionales, educación permanente, economía de la educación o formación del profesorado. ${ }^{132}$ Ahora bien, no solo sería el MEC a través de la Revista de Educación el que daría importancia a estos temas. Revistas

127 «Instituto Nacional de Asistencia y Promoción del Estudiantes», 23 de mayo de 1975, p. 5, Ministerio de Educación (05)013.000, caja 55/3694, AGA.

128 «Igualdad de oportunidades», Revista de Educación, 225-226 (1973).

129 «Acceso a la educación superior», Revista de Educación, 230-231 (1974).

130 «Problemas de Educación Postsecundaria», Revista de Educación, 232 (1974).

131 Ángeles Galino, «Concepto actual de programación», Revista de Educación, 207-208 (1970): 7-14; «Seminario Nacional permanente sobre enseñanza programada», Revista de Educación, 209 (1970): 27-29; Henri Dieuzeide, «Tecnología educativa y desarrollo de la educación», Revista de Educación, 212-213 (1971): 5-18; Gonzalo Junoy, "Satélites para la Educación», Revista de Educación, 218 (1971): 29-39; Anthony V. Frasca, «Enseñanza por medio de ordenadores», Revista de Educación, 221-222 (1972): 31-43; Vicente Ortuño, «Microenseñanza», Revista de Educación, ext. (1972): $10-16$.

132 «Conferencia de la UNESCO sobre aspectos institucionales, administrativos y financieros de las políticas culturales», Revista de Educación, 201-211 (1970): 111-113; Ricardo Díez-Hochleitner, «La educación permanente y la reforma educativa española», Revista de Educación, 217 (1971): 40-47; Luis García de Diego, «La economía de la Educación. Visión general», Revista de Educación, 236-237 (1975): 5-14; George E. Dickson, «La formación del profesorado basada en la competencia», Revista de Educación, 241 (1975): 24-44. 
como Vida Escolar, ${ }^{133}$ Bordón ${ }^{134}$ o $R E P^{135}$ divulgaron trabajos en torno a las temáticas que se identificaban con la modernización educativa.

Sin embargo, la mayoría de las publicaciones y monográficos citados no fueron fruto de la improvisación. En realidad, su origen estaba en los «Planes Nacionales de Investigación» que puso en marcha la institución encargada de organizar toda la investigación educativa en España a propia petición del Comité. ${ }^{136}$ Nos referimos, en efecto, a la red CENIDE-ICEs. Como ya hemos señalado, en las dos reuniones celebradas, el Comité señaló la importancia de planear la investigación en función de las necesidades del desarrollo. En torno a ello, el CENIDE organizó una cantidad notable de proyectos de investigación, programas educativos y seminarios de naturaleza muy amplia. Por tanto, desde sus orígenes el CENIDE comenzó a intentar cumplir el punto más importante que se le había encomendado como era el relativo al desarrollo práctico de la LGE. Teniendo en cuenta dicho aspecto, no nos debe extrañar que los primeros programas puestos en marcha fuesen aquellos relacionados con la formación del profesorado. De esta forma, el CENIDE a través de las cesiones concedidas por el PNUD, la UNESCO y la Fundación Ford emprendió un amplio programa de becas de formación en el extranjero para la mejora de la docencia y la investigación. ${ }^{137}$ Con denominaciones como «SPA/71/519»138 o «Loan 699-SP»,139 la mayoría de esas becas estuvieron destinadas a fomentar aquellos temas que el Comité había apuntado como prioritarios. Así, un número importante de becas sobre «Televisión Educativa», «Enseñanza Programada», «Enseñanza Asistida por

\footnotetext{
133 María Luisa Seriñá, «Los medios audiovisuales en la enseñanza de idiomas», Vida Escolar, 147148 (1973): 60-70.

134 María Dolores Navarro Vicedo, «La enseñanza por televisión en circuito cerrado. La experiencia docente de Marly Le Roi», Bordón, 171-72 (1970): 167-181

135 Fermín De Urmeneta, «Los métodos cibernéticos como métodos pedagógicos», REP 31, no 122 (1973): 215-225.

136 «CENIDE, Comisión del Patronato para la planificación de la investigación», marzo y abril de 1970, caja ES, AGUCM R-378, AGUCM.

137 «Comisión de formación del profesorado (CENIDE)», 11 y 12 de marzo de 1970, caja AGUCM ES, R-378, AGUCM.

138 «Proyecto SPA/71/519, 1970-1975», marzo de 1975, caja 61709, Archivo Central del Ministerio de Educación y Formación Profesional (ACMEFP).

139 «Intervención de la UNESCO, programa de becas», 22 de junio de 1971, caja 76/Carpetilla 1, ACNEC-UNESCO.
} 
Ordenador (CAI)», «Microenseñanza», «Enseñanza y movilidad social» o «Planeamiento de la educación» fueron otorgadas entre 1970 y 1975 a través de la red CENIDE-ICEs. ${ }^{140}$

Por otro lado, el CENIDE no impulsaría el desarrollo de estas temáticas solo a través de las becas de formación. El perfeccionamiento del uso de diferentes medios audiovisuales o la investigación sobre Economía de la Educación, Educación Comparada o Sociología de la Educación requería también de importantes especialistas versados en la materia. En este sentido, otro importante programa puesto en marcha por el CENIDE tuvo que ver con la invitación de consultores extranjeros de reconocido prestigio. A partir del año 1970 comenzaron a llegar especialistas como Michele Lobrot en Ciencias de la Educación, George Bereday en Educación Comparada ${ }^{141}$ o Henry H. Levin y Robert F. Arnove en Tecnología Educativa y Sociología de la Educación respectivamente. ${ }^{142}$ Pero los acuerdos alcanzados para la invitación de consultores no solo estuvo relacionada con individuos de forma independiente. Entre 1971 y 1974 la Universidad de Santiago de Compostela, por ejemplo, firmó un acuerdo con la University of Wisconsin-Madison y la Stanford University para la «mejora y formación del profesorado».143 Incluso, diferentes especialistas UNESCO -como su ATP en España, Bousquet-, ofrecieron conferencias sobre tecnología educativa en diferentes puntos del país ibérico. ${ }^{144}$

Otro de los importantes programas que puso en marcha la red CENIDE-ICEs fue el relativo a la compra de material relacionado con las técnicas de investigación recomendadas por el Comité. El impulso de la investigación educativa era, en efecto, una cuestión muy amplia que

140 «INCIE, Becarios programas internacionales», 1970-1975, caja 75/Carpetilla 1, ACNEC-UNES$\mathrm{CO}$.

141 «SPA.019.4.93 plan de operaciones España. CENIDE. Proyectos y programas UNESCO», junio de 1971, caja 61709, ACMEFP.

142 «Consultants, 1970-1975», 1970-1975, caja 2 Subseries: Education Programs in Spain, 19651981, Indiana University Archives, Peter A. Fraenkel papers, 1940-1983, bulk 1959-1976 (IUA).

143 «Programa de Colaboración entre el ICE de Santiago de Compostela y Universidades de Stanford-Wisconsin, 1971-1974», 1971, caja 3 Cooperative Programs between Spain and United Satates, 1975, IUA.

144 Jacques Bousquet, «Seminario Permanente de tecnología educativa organizado por el ICE de la Universidad de La Laguna y el CENIDE», en La problemática de las reformas educativas, 109-112. 
necesitaba de un desarrollo técnico significativo. Por este motivo, otra importante cesión de dinero hacia el CENIDE se otorgó para la compra y montaje de salas de Circuito Cerrado de Televisión (CCTV) ${ }^{145}$ y Enseñanza Asistida por Ordenador (CAI). ${ }^{146}$ Pero la compra no solo era la cuestión importante. Como ya hemos dicho, el fin último de poner en marcha todo este conglomerado técnico era investigar sobre su uso y aplicarlo en las aulas. A partir de aquí, se produjeron numerosas publicaciones sobre el uso del CCTV o CAI con este fin. ${ }^{147}$ Incluso, este último se reforzó durante los primeros años de la década de los setenta. En 1972 un informe emitido por la primera Misión UNESCO de evaluación del CENIDE dejó muy claro el asunto en este sentido. La Misión recomendó al CENIDE que «prestase particular atención a la ejecución del proyecto CAI como una tarea de alcance nacional» debido a que el mismo se estaba retrasando. ${ }^{148}$ Debido a ello, ese mismo año el CENIDE desarrolló el primer programa piloto de la UNESCO a nivel mundial sobre Enseñanza Asistida por Ordenador ${ }^{149}$ y que se suponía serviría como plan experimental a desplegar en el resto de países en vías de desarrollo. ${ }^{150}$

Por otra parte, el impulso de los modelos de investigación y formación del profesorado venido desde la UNESCO también tuvo su impacto en otros ámbitos. El CENIDE, nada más hacerse públicas las valoraciones del Comité, organizó diferentes seminarios internacionales patrocinados por la UNESCO. En 1970 se organizó en Madrid un «Seminario Internacional sobre Prospectiva de la Educación».151 Ese mismo año, también se celebraría en el CENIDE un «Seminario internacional de la

145 «Carta de J. Comiran a Monsieur Bousquet, secteur Television», 18 de diciembre de 1969, caja 61765, ACMEFP.

146 «Carta del Jefe de la Sección del CENIDE a D. Manuel Utande Igualada Director de la Unidad Administrativa del Programa del Banco Mundial», 31 de octubre de 1973, caja 61709, ACMEFP.

147 INCIE, Circuito cerrado de televisión y enseñanza (Madrid: MEC, 1975); Ordenadores en la escuela secundaria: Informe sobre una experiencia (Madrid: Universidad Complutense de Madrid/ICE de la UCM, 1975).

148 «Asistencia al CENIDE, Madrid. (Proyecto SPANED-19). Informe de la Misión de Inspección», septiembre de 1972, p. 23, caja 75/Carpetilla 1, ACNEC-UNESCO.

149 «The Plan for the Use of Computers in the Education of Teachers», enero de 1972, caja 3 Cooperative Programs between Spain and United States, 1975, IUA.

150 Díez-Hochleitner, «La reforma educativa de la LGE de 1970», 269.

151 «Seminario internacional sobre prospectiva de la educación», abril de 1970, caja 325/Carpetilla 2, ACNEC-UNESCO. 
UNESCO sobre el uso de modelos matemáticos en la planificación de la educación».152 Temas todos ellos que se volverían a repetir durante estos años como la organización de un seminario sobre la adaptación de la educación a las necesidades económicas a través de una especie de formación dual, denominado «educación recurrente». ${ }^{153}$

No obstante, la dirección de ciertas políticas educativas experimentaría una transformación notable con la llegada de la Transición a la democracia. Como sabemos, toda política educativa está sujeta a las presiones y transformaciones contextuales que ejercen determinados grupos sociales en un momento determinado. La muerte del dictador, supuso la entrada de nuevos actores educativos. Con ellos, también se agrandaron los espacios de debate y las prioridades de investigación en educación. El auge, por ejemplo, de los Movimientos de Renovación Pedagógica, las Alternativas para la Enseñanza u otros nuevos actores internacionales como los acuerdos firmados con la Unión Europea, ${ }^{154}$ transformaron, en cierta medida, los espacios educativos y las direcciones desde las cuales producir procesos de transferencia educativa. Por otro lado, la Teoría de la Modernización comenzaría a sufrir una crisis importante y con ella alguno de sus modelos educativos. ${ }^{155}$ Sea como fuere, el espacio abierto por la llegada de la democracia en España transformó algunas tendencias en educación que no podemos abordar aquí. Lo importante a destacar hasta este punto, es la importancia que la UNESCO tuvo en el origen y primeros desarrollos de la LGE.

\section{CONCLUSIONES}

El inicio de las influencias y convergencias que el franquismo estableció con la UNESCO no es sencillo de detectar. No obstante, desde el origen mismo del organismo internacional la dictadura parecía estar

\footnotetext{
152 «Seminario internacional de la UNESCO sobre el uso de modelos matemáticos en la planificación de la educación», junio de 1970, caja 325/Carpetilla 2, ACNEC-UNESCO.

153 Millán Arroyo Simón, «Recurrent education: Trends and issues», 9 de septiembre de 1975, caja 61703, ACMEFP.

154 Véase Tamar Groves, "A foering model of teacher education and its local appropriation: the English teachers`centres in Spain», History of Education 44, n. ${ }^{\circ} 3$ (2015): 355-370.

155 Véase como ejemplo Martin Carnoy, «The economic costs and returns to educational television», Ekistics 40, n. ${ }^{\circ} 240$ (1975): 370-384.
} 
al tanto de las cuestiones que tenían que ver con el mundo educativo. Sin embargo, a partir de los años cincuenta del siglo XX, con la apertura y acuerdos firmados con la UNESCO, el régimen experimentó un mayor acercamiento a la comunidad internacional y con todos aquellos programas educativos que se desarrollaban en otros países durante estos años. Tanto es así, que desde 1953 se comenzó a debatir ampliamente la concepción educativa que la UNESCO quería poner en marcha en los diferentes países que estaban dentro de su órbita.

A partir de aquí, las instituciones educativas de la dictadura empezarían a debatir sobre la importancia de intentar poner en marcha un sistema educativo apoyado en la universalización del mismo. Políticas sobre alfabetización, desarrollo de la comprensión internacional y, lo más importante, la educación como un órgano fundamental del desarrollo económico fueron ideas que empezaron a ponerse en marcha dentro del franquismo. La llegada de la década de los sesenta acrecentó esta visión educativa y esa nueva concepción que había nacido unos años antes comenzó a formar parte, de manera principal, de las instituciones educativas españolas. Ya nadie parecía poner en duda que el sistema educativo debía ser organizado en función de las necesidades económicas y sociales y que el mismo tenía que estructurarse a través de la herramienta que la UNESCO había puesto como central: el planeamiento educativo.

A finales de la citada década, llegó una primera misión de inspección. Conocida como UNESCO-BIRD-FAO, la misma recomendó a la dictadura poner en marcha un plan amplio de reformas educativas. El entonces recién creado MEC no se amedrentó con la encomienda y aceptó el reto de comenzar una reforma estructural de todo el sistema educativo. Bajo esta concepción, el nuevo ministro Villar Palasí y su nuevo secretario técnico llegado de la UNESCO, Díez-Hochleitner, resolvieron pedir una nueva cesión económica al acuerdo que había firmado la UNESCO y el BM en 1968. Ello supuso la llegada de un Comité de expertos internacionales que se reunió para debatir el Libro Blanco. Bajo las propuestas sugeridas por el Comité, la LGE vio la luz y con ella una cantidad importante de proyectos educativos, seminarios, publicaciones, consultores y becas fueron otorgadas para modernizar el sistema educativo español en la línea que se hacía en otros países a nivel mundial. 
En este sentido, España no aparecía como un islote educativo. Era uno más de los países con un nivel de desarrollo medio-alto que utilizaba o, mejor dicho, organizaba su sistema educativo con el objetivo de conseguir un mayor desarrollo económico. Dicho de otro modo, las instituciones educativas franquistas operaron bajo el mismo concepto de educación que había desarrollado la UNESCO. En definitiva, el origen de la LGE debe ser entendido como un proceso de larga duración que se inició en torno a los debates educativos que la UNESCO quiso implementar a nivel global desde principios de los cincuenta dentro del contexto de la Guerra Fría.

\section{Notas sobre los autores}

Mariano González-Delgado es profesor contratado doctor en el Departamento de Historia y Filosofía de la Ciencia, la Educación y el Lenguaje, Universidad de la Laguna. Su investigación se centra en diferentes líneas de trabajo dentro de la historia de la educación. Entre ellas, destacan la historia del currículum, el análisis de los libros de texto y las influencias internacionales y modernización educativa durante el franquismo. Ha publicado diferentes trabajos sobre estos temas en revistas como History of Education, British Journal of Educational Studies o Journal of Educational Media, Memory and Society y en libros como Trasnational Perspectives on Curriculum History (editor), Textbooks and War o Teaching Modernization: Spanish and Latin American Educational Reform in the Cold War. Ha sido investigador visitante en el UCL Institute of Education de la Universidad de Londres (2014) y en la Uppsala University (2018). Actualmente trabaja en el proyecto de investigación Modernización, desarrollo y democratización. El papel de las potencias europeas occidentales y de las organizaciones internacionales en el cambio político y social en España, concedido por el Ministerio de Ciencia e Innovación.

TAmar Groves es profesora contratada doctora en el Departamento de Ciencias de la Educación de la Universidad de Extremadura, Cáceres. Sus líneas de investigación son: Historia Política y Social de la educación en la España contemporánea, Formación del Profesorado y Educación Superior, Educación Internacional y transferencias educativas, Educación Cívica y movimientos sociales en el ámbito educativo. Ha 
publicado libros como Teachers and the Struggle for Democracy in Spain, 1970-1985 (Palgrave Macmillan, 2013) o capítulos de libros en diferentes editoriales como Routledge, Sílex o Berghahn Books y artículos científicos en prestigiosas revistas como Journal of Social History, European History Quarterly, Paegagogica Historica, War and Society y History of Education. En la actualidad colabora en un proyecto de investigación del Peace Research Institute en Oslo acerca de iniciativas educativas en Asia, África y el Próximo Oriente y en el proyecto nacional Connecting History of Education. Redes internacionales, producción científica y difusión global, financiado por el Ministerio de Ciencia e Innovación.

\section{REFERENCIAS}

«Acceso a la educación superior». Revista de Educación, 230-231 (1974).

«Conferencia de la UNESCO sobre aspectos institucionales, administrativos y financieros de las políticas culturales». Revista de Educación, 201-211 (1970): 111-113.

«Educación y desarrollo». Revista de Educación, 178 (1966): 93.

«El CENIDE y las investigaciones sobre educación». Revista de Educación, 209 (1970): 5-14.

«El Ministro de Educación y Ciencia explica la política del nuevo Ministerio». Revista de Educación, 178 (1966): 90.

«Igualdad de oportunidades». Revista de Educación, 225-226 (1973).

«II Reunión del Comité de Cooperación Internacional para la Reforma de la Educación en España». Revista de Educación, 205 (1969): 54-58.

«Informe final del Comité de Cooperación Internacional para la Reforma de la Educación en España». Revista de Educación, 202 (1969): 58-64.

«Informe sobre el viaje a Estados Unidos de la Comisión de Profesores Universitarios encargados de estudiar la organización de los Institutos de Ciencias de la Educación». Revista de Educación, 206 (1969): 55-60.

«Investigación y desarrollo». Revista de Educación, 190 (1967): 85-86.

«La UNESCO y la investigación sobre planeamiento». Revista de Educación, 191 (1967): 144.

«Misión y servicio de la Oficina Internacional de Educación». Revista de Educación, 57 (1945): 67-70.

«OCDE: Desarrollo de la enseñanza española». Revista de Educación, 175 (1965): 89.

«Panorama económico de la protección escolar». Revista de Educación, 71 (1957): 58-60. 
«Planeamiento escolar y necesidades económico sociales», Revista de Educación, 170 (1965): 134-135.

«Problemas de Educación Postsecundaria». Revista de Educación, 232 (1974).

«Prólogo». Revista de Educación, 210-211 (1970): 4.

«Seminario Nacional permanente sobre enseñanza programada». Revista de Educación, 209 (1970): 27-29.

Barceló-Bauzà, Gabriel, Francisca Comas-Rubí y María del Mar Del Pozo. «La práctica escolar durante los primeros años del franquismo». História da Educação 22, n. ${ }^{\circ} 54$ (2018): 334-357.

Bousquet, Jacques. «El Centro Nacional de Investigaciones para el Desarrollo de la Educación». Perspectivas, 0 (1972): 155-159.

Bousquet, Jacques. «Replantear el problema de la educación». Revista de Educación, 69 (1957): 1-4.

Bousquet, Jacques. «Tendencias del planeamiento educativo en 1968». Revista de Educación, 201 (1969): 43-47.

Bousquet, Jacques. La problemática de las reformas educativas. Madrid: MEC, 1974.

Cabrera, Miguel Á. «The discursive origins of the welfare state: Spanish social reformism, 1870-1900». Journal of Social History 52, n. ${ }^{\circ} 4$ (2019): 1165-1184.

Canales, Antonio F. «From soul to matter: the new Spanish Francoist pedagogy's plunge into experimental pedagogy and the influence of Raymond Buyse». Paedagogica Historica 55, n. 3 (2019): 451-469.

Carnoy, Martin. "The economic costs and returns to educational television», Ekistics 40, n. ${ }^{\circ} 240$ (1975): 370-384.

CEDODEP. La escuela unitaria completa: Curso organizado por el Gobierno español como colaboración al Proyecto Principal de la UNESCO. Madrid: CEDODEP, 1960.

Christensen, Ivan L. y Christian Ydesen. «Routes of Knowledge: Toward a Methodological Framework for Tracing the Historical Impact of International Organizations». European Education 47, n. ${ }^{\circ} 3$ (2015): 274-288.

Corrales Morales, David. «Much Ado about Nothing? Lights and Shadows of the World Bank's Support of Spanish Aspirations to Educational Modernization (1968-1972)». En Teaching Modernization Spanish and Latin American Educational Reform in the Cold War, editado por Óscar J. Martín García y Lorenzo Delgado Gómez-Escalonilla, 127-149. New York: Berghahn Books, 2020).

De Puelles Benítez, Manuel. Educación e ideología en la España Contemporánea. Barcelona: Labor, 1980.

De Reyna, Guillermo. «Los métodos audio-visuales en la educación fundamental. Notas al congreso de Milán». Revista de Educación 1, n. 2 (1952): 164$167,167$. 
De Urmeneta, Fermín. «Los métodos cibernéticos como métodos pedagógicos». REP 31, no 122 (1973): 215-225.

Del Pozo, María del Mar y Sjaak Braster. «The Reinvention of the New Education Movement in the Franco Dictatorship (Spain, 1936-1976)». Paedagogica Historica 42, n. ${ }^{\circ}$ 1-2 (2006): 109-126.

Del Pozo, María del Mar. "Community and the myth of the ideal school: circulation and appropriation of the Hamburg Gemeinschaftsschulen in Spain (1922-1933)». Paedagogica Historica 50, n. ${ }^{\circ} 5$ (2014): 599-614.

Delgado Gómez-Escalonilla, Lorenzo. «Modernizadores y tecnócratas. Estados Unidos ante la política educativa y científica de la España del Desarrollo». Historia y Politica, 34 (2015): 113-146.

Dickson, George E. «La formación del profesorado basada en la competencia». Revista de Educación, 241 (1975): 24-44.

Dieuzeide, Henri. «Tecnología educativa y desarrollo de la educación». Revista de Educación, 212-213 (1971): 5-18.

Díez-Hochleitner, Ricardo. «La educación permanente y la reforma educativa española». Revista de Educación, 217 (1971): 40-47.

Díez-Hochleitner, Ricardo. "La reforma educativa de la LGE de 1970. Datos

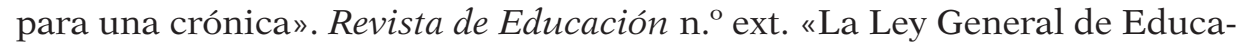
ción veinte años después» (1992): 261-278, 262.

Duedahl, Poul. "Out of the House: On the Global History of UNESCO, 19452015». En A History of UNESCO: Global Actions and Impacts, editado por Poul Duedahl, 3-23. London: Palgrave Macmillan, 2016.

Eckhardt Fuchs, "History of Education beyond the Nation? Trends in Historical and Educational Scholarship». En Connecting Histories of Education: Transnational and Cross-Cultural Exchanges on (Post-) Colonial Education, editado por Barnita Bagchi, Eckhardt Fuchs y Kate Rousmaniere, 11-26. New York: Berghahn Books, 2014.

Escolano, Agustín. «Los comienzos de la modernización pedagógica en el Franquismo (1951-1964)». Revista Española de Pedagogía (REP) 50, n. ${ }^{\circ} 192$ (1992): 289-310.

Fernández Fernández, Javier. «Una experiencia pedagógica de la escuela nueva: Carmen Conde y el Orfanato Nacional de El Pardo». Historia y Memoria de la Educación, 10 (2019): 485-521.

Fernández Soria, Juan Manuel. «Presentación. Influencias europeas en la política educativa española del siglo XX (presencias y ausencias, temas para la investigación histórico-educativa)». Historia de la Educación. Revista Interuniversitaria, 24 (2005): 27-37.

Ferraz Lorenzo, Manuel. «Un ejemplo de renovación pedagógica en Canarias durante los años 30: Tras el rastro y los retos de las técnicas Freinet». História da Educação 20, n. ${ }^{\circ} 50$ (2016): 157-175. 
Fraga Iribarne, Manuel, editor. La educación en una sociedad de masas. Madrid: Cultura Hispánica, 1954.

Frasca, Anthony V. «Enseñanza por medio de ordenadores». Revista de Educación, 221-222 (1972): 31-43.

Fuchs, Eckhardt. "Children's Rights and Global Civil Society». Comparative Education 43, n. 3 (2007): 393-412.

Galino, Ángeles. «Concepto actual de programación». Revista de Educación, 207-208 (1970): 7-14.

Galino, Ángeles. «La dificultad número uno». Revista de Educación, 203 (1969): 7-13.

García de Diego, Luis. «La economía de la Educación. Visión general». Revista de Educación, 236-237 (1975): 5-14.

García Hoz, Víctor. «Discurso de clausura». REP 23, n. o 91-92 (1965): 845-862.

García Hoz, Víctor. «Reforma cualitativa de la educación». REP 30, n. ${ }^{\circ} 127$ (1972): 3-10.

González-Arizmendi, Francisco. «La evolución actual de la enseñanza profesional (Notas tomadas de informes de la OCDE)». Revista de Educación, 202 (1969): 65-68.

González-Delgado, Mariano y Tamar Groves, «UNESCO mediation in Francoist curriculum policy: The case of educational television in Spain». En Transnational Perspectives on Curriculum History, editado por Gary McCulloch, Ivor Goodson y Mariano González-Delgado, 83-107. London: Routledge, 2020.

González-Delgado, Mariano y Tamar Groves. «Educational Transfer and Local Actors: International Intervention in Spain during the Late Franco Period». En Teaching Modernization Spanish and Latin American Educational Reform in the Cold War, editado por Óscar J. Martín García y Lorenzo Delgado Gómez-Escalonilla, 101-126. New York: Berghahn Books, 2020.

González-Delgado, Mariano y Tamar Groves. «La enseñanza programada, la UNESCO y los intentos por modificar el currículum en la España desarrollista (1962-1974)». Espacio, Tiempo y Educación 4, n. ${ }^{\circ} 2$ (2017): 73-100.

González-Delgado, Mariano, Manuel Ferraz Lorenzo y Cristian Machado-Trujillo. "The concept of the State in textbooks: Analysis and reinterpretation during the Spanish Transition to Democracy (1976-1986)». British Journal of Educational Studies 68, n. 3 (2019): 331-347.

Goodman, Joyce, Gary McCulloch y William Richadson. «'Empires overseas' and 'empires at home': postcolonial and transnational perspectives on social change in the history of education». Paedagogica Historica 45, n. ${ }^{\circ} 6$ (2009): 695-706.

Gozzer, Giovanni. "Consideraciones sobre la "inercia” de las estructuras ecuaciones». Revista de Educación, 206 (1969): 7-11. 
Groves, Tamar. «A foering model of teacher education and its local appropriation: the English teachers ' centres in Spain». History of Education 44, n. 3 (2015): 355-370.

Hernández Díaz, José M. ${ }^{\text {a }}$ (coord.). Francia en la educación de la España contemporánea (1808-2008). Salamanca: Ediciones Universidad de Salamanca, 2011.

Hernández Díaz, José M. ${ }^{a}$ (coord.). La pedagogía belga y la innovación educativa en España (1900-1936). Salamanca: Ediciones Universidad de Salamanca, 2019.

Husén, Torsten. «Dos décadas de investigación educativa en Suecia». Revista de Educación, 210-211 (1970): 12-26.

Husén, Torsten. «El modelo de las escuelas del mañana». Revista de Educación, 215-216 (1971): 93-104.

Husén, Torsten. "Reforma y tradición del sistema escolar ante las necesidades cambiantes de la sociedad: algunas experiencias suecas». Revista de Educación, 212-213 (1971): 53-58

Husén, Torsten. Para una igualdad de oportunidades. Madrid: ICCE y INCIE, 1978.

Igelmo-Zaldívar, Jon y Gonzalo Jover Olmeda. «Cuestionando la narrativa del aprendizaje servicio a partir de dos iniciativas de extensión social universitaria de orientación católica en la década de 1950 en España». Utopía y praxis latinoamericana: revista internacional de filosofía iberoamericana y teoría social, 87 (2019): 151-162.

INCIE, Circuito cerrado de televisión y enseñanza. Madrid: MEC, 1975.

Jones, Phillip W. y David Coleman. The United Nations and Education Multilateralism, Development and Globalization. New York: Routledge, 2005.

Jover, Gonzalo y Blanca Thoilliez Ruano. «La pedagogía "au pluriel” y su incidencia en la reformulación del conocimiento teórico de la educación en España». En Francia en la educación de la España contemporánea (18082008), editado por José María Hernández Díaz, 2019-247. Salamanca: Universidad de Salamanca, 2011.

Junoy, Gonzalo. «Satélites para la Educación». Revista de Educación, 218 (1971): 29-39.

Kulnazarova, Aigul y Christian Ydesen. «The nature and methodology of UNESCO's educational campaigns for international understanding». En UNESCO without Borders: Educational campaings for international understanding, editado por Aigul Kulnazarova y Christian Ydesen, 3-12. London: Routledge, 2017.

Langlois, Susanne. «And Action! UN and UNESCO Coordinating Information Films, 1945-1951». En A History of UNESCO: Global Actions and Impacts, editado por Poul Duedahl, 73-94. London: Palgrave Macmillan, 2016. 
Lindo-Fuentes, Héctor. «Educational Television in El Salvador and Modernisation Theory». Journal of Latin American Studies, 41 (2009): 757-792.

Lorenzo Gelices, Feliciano. «El derecho a la enseñanza y su protección jurídica por el estado y la sociedad: sus problemas». Revista de Educación, 80 (1958): 61-66.

Mahamud Angulo, Kira y Cecilia Milito Barone. «Estancias y consultores para la formación del profesorado. Un pilar estratégico del intercambio cultural ente España y Estados Unidos (1960-1976)». En Modernización educativa y socialización política: Contenidos curriculares y manuales escolares en España durante el tardofranquismo y la transición democrática, editado por Manuel Ferraz Lorenzo, 151-190. Madrid: Morata, 2020.

Maíllo, Adolfo. «La comprensión entre Oriente y Occidente». Vida Escolar, 4 (1959): 42-44.

Maíllo, Adolfo. «La Escuela Media, necesidad nacional». Revista de Educación, 155 (1963): 109-118.

Mainer, Juan. La forja de un campo profesional. Pedagogía y didáctica de las Ciencias Sociales en España (1900-1970). Madrid: CSIC, 2009.

Mariuzzo, Andrea. "American cultural diplomacy and post-war educational reform: James Bryant Conant's misión to Italy in 1960». History of Education 45, n. ${ }^{\circ} 3$ (2016): 352-371, 353.

Martín García, Óscar J. "A complicated mission: The United States and Spanish students during the Johnson administration». Cold War History 13, n. ${ }^{\circ} 3$ (2013): 311-329.

Martín García, Óscar J. «Una utopía secular. La teoría de la modernización y la política exterior estadounidense en la Guerra Fría». Historia y Política, 34 (2015): 27-52.

Martín García, Óscar J. y Lorenzo Delgado Gómez-Escalonilla. «Educational Reform, Modernization, and Development: A Cold War Transnational Process». En Teaching Modernization Spanish and Latin American Educational Reform in the Cold War, editado por Óscar J. Martín-García y Lorenzo Delgado Gómez-Escalonilla, 1-39. New York: Berghahn Books, 2020.

Martín García, Óscar J. y Rosa Mgnúsdottir. «Machineries of Persuasion: European Soft Power and Public Diplomacy during the Cold War». En Machineries of Persuasion: European Soft Power and Public Diplomacy during the Cold War, editado por Óscar J. Martín García y Rosa Mgnúsdottir, 1-15. Berlin: De Gruyter Oldenbourg, 2019.

Martínez Val, José M. «Educación y pacifismo (La formación del hombre para la paz)». REP 5, n. ${ }^{\circ} 18$ (1947): 253-268.

Martínez Valle, Carlos. "Active Methods and Social Secularization in School Catechesis during the Franco Dictatorship (1939-1975): A Transfer in a Cultural System in Change». En Catholic Education in the Wake of Vatican II, 
editado por Rosa Bruno-Jofré y Jon Igelmo-Zaldívar, 69-91. Toronto: University of Toronto Press, 2017.

McAnany, Emile G. Saving the World: A Brief History of Communication for Development and Social Change. Baltimore: University of Illinois Press, 2012.

McCulloch, Gary y Roy Lowe. «Introduction: Centre and periphery: networks, space and geography in the history of education». History of Education 32, n. 5 (2003): 457-459.

McCulloch, Gary, Ivor Goodson y Mariano González-Delgado. «Introduction. Curriculum history and transnational perspectives for studies: generating debates on educational research». En Transnational Perspectives on Curriculum History, editado por Gary McCulloch, Ivor Goodson y Mariano González-Delgado, 1-11. London: Routledge, 2020.

McCulloch, Gary. The Struggle for the History of Education. London: Routledge, 2011.

MEC. La educación en España. Bases para una política educativa. Madrid: MEC, 1969.

MEN. España y la UNESCO. Colaboración al Proyecto Principal Extensión y Perfeccionamiento de la Educación Primaria en América latina. Madrid: MEN, 1962.

MEN-UNESCO. La educación y el desarrollo económico-social. Planeamiento integral de la educación. Objetivos de España para 1970. Madrid: MEN-UNESCO, 1962.

Meyer, John W., Ramirez, Francisco O., Rubinson, Richard y Boli, John. «The World Educational Revolution, 1950-1970». Sociology of Education 50, n. ${ }^{\circ} 4$ (1977): 242-258.

Navarro Vicedo, María Dolores. «La enseñanza por televisión en circuito cerrado. La experiencia docente de Marly Le Roi». Bordón, 171-72 (1970): 167181.

Noriega Álvarez, Juan. «Bases para el Planeamiento de la biblioteca escolar como centro de proyección cultural». Vida Escolar, 113-114 (1969): 16-27.

OCDE-MEN. «la educación española en el desarrollo económico». Revista de Educación, 147 (1962): 25-29.

Oliveros, Ángel. XXV años de la Comisión Nacional Española de Cooperación con la UNESCO. Madrid: UNESCO-MEC, 1978.

Ordenadores en la escuela secundaria: Informe sobre una experiencia. Madrid: Universidad Complutense de Madrid/ICE de la UCM, 1975.

Ortiz de Solórzano, José M. «La educación en una sociedad de masas». Revista de Educación, 14 (1953): 237-243.

Ortuño, Vicente. «Microenseñanza». Revista de Educación, ext. (1972): 10-16. 
Ossenbach, Gabriela y Alberto Martínez Boom. «Itineraries of the discourses on development and education in Spain and Latin America (circa 1950-1970)». Paedagogica Historica 47, n. 5 (2011): 679-700.

Ossenbach, Gabriela y Tamar Groves. «Entre la mitificación y la crítica: el cine y los medios audiovisuales en la escuela primaria en España en el tardofranquismo y la transición, 1958-1982». Cahiers de civilisation espagnole con contemporaine, 11 (2013): 1-12;

Paredes Grosso, Juan M. «Notas actuales sobre educación y desarrollo». Revista de Educación, 179 (1966): 122-127.

Pulpillo, Ambrosio, J. «Planeamiento del trabajo escolar por cursos». Vida escolar, 51-52 (1963): 5-7.

Roldán-Vera, Eugenia y Eckhardt Fuchs. «Introducction: The Transnational in the History of Education». En The Transnational in the History of Education: Concepts and Perspectives, editado por Eugenia Roldán-Vera y Eckhardt Fuchs, 1-47. Cham: Palgrave Macmillan, 2019.

Rubio García-Mina, Jesús. «Importante discurso del Ministro de Educación nacional en la UNESCO». Vida Escolar, 25 (1961): 25-29.

Rudolph, John L. Scientist in the Classroom. The Cold War Reconstruction of American Science Education. New York: Palgrave, 2002.

Ruiz-Giménez, Joaquín. «España, en la UNESCO». Revista de Educación, 26 (1954): 157-160.

Secadas, Francisco. «Criterios para una reforma de la educación». REP 57, n. ${ }^{\circ} 105$ (1969): 3-56.

Seriñá, María Luisa. «Los medios audiovisuales en la enseñanza de idiomas». Vida Escolar, 147-148 (1973): 60-70.

Snowden, John. «Lazos docentes internacionales». Revista de Educación, 68 (1947): 91-93.

Tena Artigas, Antonio. «La Educación y el primer Plan de Desarrollo». Revista de Educación, 180 (1966): 26-31.

Tena Artigas, Joaquín. «Economía y Educación». Notas y Documentos, 1 (1961): 3-8.

Terrón, Aida, Josep M. Comelles y Enrique Perdiguero-Gil. «Schools and health education in Spain during the dictatorship of General Franco (1939-1975)». History of Education Review 46, n. ${ }^{\circ} 2$ (2017): 208-223.

Trölher, Daniel. «The technocratic Momentum after 1945, the Development of Teaching Machines, and Sobering Results». Journal of Educational, Media, Memory and Society 5, n. 2 (2013): 1-19.

Utande Igualada, Manuel. «Una Ley general de Educación». Revista de Educación, 99 (1959): 1-3.

Viñao, Antonio. «La recepción de Rousseau en la formación inicial del magisterio primario (España, siglo 20)». Revista História da Educação 17, n. 41 (2013): 11-28. 